\title{
Magnetic resonance spectroscopic imaging of tumor metabolic markers for cancer diagnosis, metabolic phenotyping, and characterization of tumor microenvironment
}

\author{
Qiuhong He ${ }^{\mathrm{a}, \mathrm{b}, *}$, Ray Z. Xu ${ }^{\mathrm{b}}$, Pavel Shkarin ${ }^{\mathrm{b}}$, Giuseppe Pizzorno ${ }^{\mathrm{b}}$, Carol H. Lee-French ${ }^{\mathrm{b}}$, \\ Douglas L. Rothman ${ }^{\mathrm{b}}$, Dikoma C. Shungu ${ }^{\mathrm{c}}$ and Hyunsuk Shim ${ }^{\mathrm{d}}$ \\ ${ }^{a}$ Memorial Sloan-Kettering Cancer Center, Departments of Medical Physics and Radiology, 1275 York Avenue, \\ New York, NY 10021, USA \\ ${ }^{\mathrm{b}}$ Magnetic Resonance Center, Yale University School of Medicine, New Haven, CT 06520, USA \\ ${ }^{\mathrm{c} D e p a r t m e n t ~ o f ~ R a d i o l o g y, ~ C o l l e g e ~ o f ~ P h y s i c i a n s ~ \& ~ S u r g e o n s, ~ C o l u m b i a ~ U n i v e r s i t y, ~ N e w ~ Y o r k, ~ N Y ~ 10032, ~ U S A ~}$ \\ ${ }^{\mathrm{d}}$ Winship Cancer Institute, Emory University, 1365C Clifton Road, N.E., C5008, Atlanta, GA 30322, USA
}

\begin{abstract}
Cancer cells display heterogeneous genetic characteristics, depending on the tumor dynamic microenvironment. Abnormal tumor vasculature and poor tissue oxygenation generate a fraction of hypoxic tumor cells that have selective advantages in metastasis and invasion and often resist chemo- and radiation therapies. The genetic alterations acquired by tumors modify their biochemical pathways, which results in abnormal tumor metabolism. An elevation in glycolysis known as the "Warburg effect" and changes in lipid synthesis and oxidation occur. Magnetic resonance spectroscopy (MRS) has been used to study tumor metabolism in preclinical animal models and in clinical research on human breast, brain, and prostate cancers. This technique can identify specific genetic and metabolic changes that occur in malignant tumors. Therefore, the metabolic markers, detectable by MRS, not only provide information on biochemical changes but also define different metabolic tumor phenotypes. When combined with the contrast-enhanced Magnetic Resonance Imaging (MRI), which has a high sensitivity for cancer diagnosis, in vivo magnetic resonance spectroscopic imaging (MRSI) improves the diagnostic specificity of malignant human cancers and is becoming an important clinical tool for cancer management and care. This article reviews the MRSI techniques as molecular imaging methods to detect and quantify metabolic changes in various tumor tissue types, especially in extracranial tumor tissues that contain high concentrations of fat. MRI/MRSI methods have been used to characterize tumor microenvironments in terms of blood volume and vessel permeability. Measurements of tissue oxygenation and glycolytic rates by MRS also are described to illustrate the capability of the MR technology in probing molecular information non-invasively in tumor tissues and its important potential for studying molecular mechanisms of human cancers in physiological conditions.
\end{abstract}

\section{Introduction}

Since its first observation about half a century ago, magnetic resonance spectroscopy (MRS) has evolved

*Corresponding author: Magnetic Resonance Research Center B-804 PUH-UPMC, Department of Radiology and Bioengineering, University of Pittsburgh Cancer Institute, University of Pittsburgh, 200 Lothrop Street, Pittsburgh, PA 15213, USA. Tel.: +1 412647 3088; Fax: +1 412647 9800; E-mail: heq@upmc.edu. into a practical technique with a great impact on biology and medicine. It is highly sensitive to the chemical environment of biomolecules and has been used to solve three-dimensional (3D) protein structures and to probe protein dynamics and interactions in aqueous solutions [1]. Magnetic resonance imaging (MRI) detects the tissue water signal for imaging the anatomical organ structures. Because it provides high-resolution anatomical images without the use of ionizing radiation, MRI is powerful in identifying neoplastic changes 
in soft tissues. The MRI sensitivity for cancer detection has been enhanced by the use of exogenous contrast agents. Magnetic resonance spectroscopic imaging (MRSI) detects in vivo the tissue distributions of metabolites and certain proteins. The technique has been used to monitor biochemical and metabolic phenotypic changes non-invasively in animals and humans. This article reviews the tumor metabolic changes detectable by MRS and the advanced MRI and MRS techniques that can identify the tumor-specific markers for oncologic changes and cancer diagnosis.

\section{Molecular basis of tumor metabolism-Warburg effect as a consequence of genetic abnormality of cancer}

Neoplastic cells need to activate specific metabolic pathways to develop into 3D spheroids and solid tumors [2-4]. Microregions of heterogeneous cell environments [5] are associated with the development of abnormal vascularization in malignant tumors, which often consist of distended capillaries with leaky walls and sluggish flow, as compared with the regular, ordered vasculature of normal tissues. Despite the constant effort of tumor cells to recruit new blood vessels, there are significant gradients of critical factors for cell growth, such as oxygen, glucose, other nutrients, and growth factors. Hypoxia occurs in tumor cells that are $100-150 \mu \mathrm{m}$ away from the nearest blood vessel and tends to be widespread in solid tumors observed as multifoci (or "multiforme"). The anaerobic metabolism of glucose provides a major energy source for tumor cells in hypoxic regions. The ability of tumor cells to endure profound hypoxia indicates that their adaptation to hypoxic conditions is a crucial step in tumor progression. For example, hypoxia also contributes to processes that directly favor malignant cell progression through effects on the expression and activity of tumor suppressor proteins such as $\mathrm{p} 53$. It appears that hypoxia can act as a selective physiological pressure against the survival of wild-type p53 cells in a tumor, thus favoring oncogenesis through enrichment of the population of mutant p53 cells [6].

A striking common feature of tumor cells is the production of high levels of lactic acid, as Warburg observed 70 years ago [7]. Tumors that use glycolysis for their energy supply may have a growth advantage over tumors that use the Tricarboxylic acid cycle (TCA) [8, 9]. In rat thymocytes, aerobic glycolysis may be a means to minimize oxidative stress during the phases of the cell cycle, resulting in enhanced proliferation [10, 11]. An understanding of the regulation of glycolytic enzyme gene expression is beginning to emerge with the characterization of glycolytic enzyme gene promoters.

The last enzyme of glycolysis, lactate dehydrogenase A (LDH-A) is an epidermal growth factor, cAMP, and phorbol ester-inducible protein that has been a widespread prognostic tumor marker [12-15]. The elevated LDH-A levels will result in increased production of lactic acid within tumor cells, which may result in cell death due to acidosis. The ability to upregulate proton extrusion may be important for tumor cell survival. Such microenvironmental factors may be involved in the development of resistant tumor cells in conventional therapy.

The physiological heterogeneity within solid tumors derives from the specific microenvironment and genetic alterations of each tumor. Until now, targeting tumor physiology for anticancer therapy has received less attention than approaches based on the cellular and molecular differences between transformed and untransformed cells. If information regarding the tumor microenvironment (e.g., hypoxia conditions of cancer cells) is available, specific anticancer therapy can be designed accordingly for individual patients.

\section{Emerging MRS techniques in preclinical studies of cancers}

Magnetic resonance spectroscopy is sensitive to tumor physiology and biochemistry $[16,17]$. In the early studies using ${ }^{31} \mathrm{P} \mathrm{MRS}, \mathrm{PME} / \mathrm{ATP}_{\beta}$ ratios measured in the "benign" (Stage IV-S) and "malignant" (Stage IV) neuroblastoma were shown to correlate with tumor progression and regression [17]. (PME denotes phosphomonoester and ATP stands for adenosine triphosphate.) For Stage IV neuroblastoma, the PME/ATP $\beta$ ratio correlated with tumor progression during growth and with regression during treatment; in Stage IV-S neuroblastoma, no change of $\mathrm{PME} / \mathrm{ATP}_{\beta}$ ratio was observed during tumor progression or regression. A later study of 20 patients with soft-tissue sarcoma at Duke University found that intracellular tumor $\mathrm{pH}$ measured by ${ }^{31} \mathrm{P}$ MRS and tissue water $\mathrm{T}_{2}$ relaxation measured by MRI together can predict the therapeutic response with $90 \%$ sensitivity and $80 \%$ specificity [18]. Collectively, these results suggest that human cancer has specific metabolic characteristics that may be exploited to obtain useful diagnostic and prognostic information. 


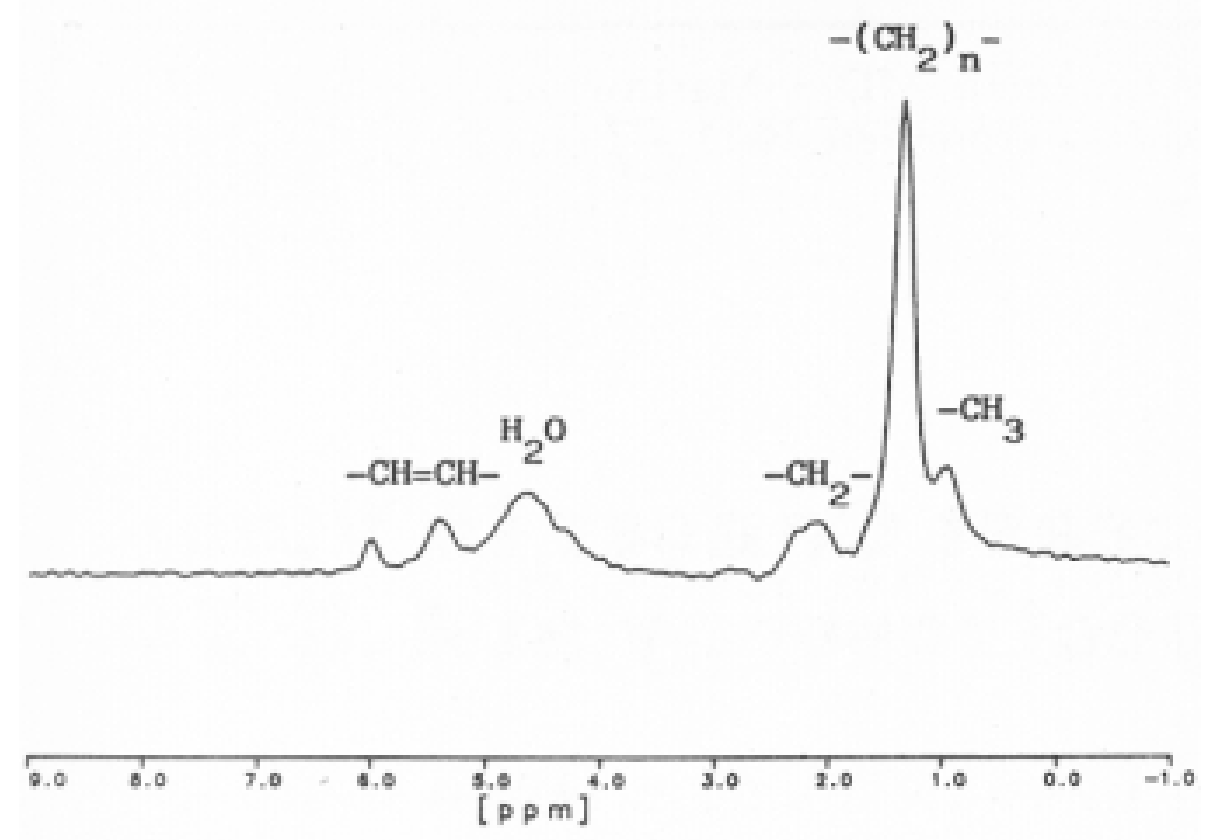

Fig. 1. Lipid and water resonances dominate a typical proton spectrum of breast tissue from a breast cancer patient [29]. (with permission).

${ }^{31} \mathrm{P}$ MRS investigations of breast cancer revealed large signals of PME and PDE (phosphodiesters) in human breast tumors. A decrease in PME levels was associated with responding disease, and an increase in PME levels was associated with disease progression. The phosphocholine (PC) concentration was associated significantly with the tumor grades [19].

\subsection{High sensitivity of in vivo ${ }^{1} H$ MRS for tissue metabolite detection}

The low sensitivity of ${ }^{31} \mathrm{P}$ MRS detection limits its utility in cancer management. The voxel size localized by ${ }^{31} \mathrm{P}$ MRS often is too large to detect small tumors and study tumor heterogeneity $\left(27 \mathrm{~cm}^{3}\right.$ at $1.5 \mathrm{~T}, 8 \mathrm{~cm}^{3}$ at $4 \mathrm{~T}$ and $4 \mathrm{~cm}^{3}$ at $\left.7 \mathrm{~T}\right) .{ }^{1} \mathrm{H}$ MRS improves the detection sensitivity of metabolites by employing protons, the most abundant and sensitive nuclei in metabolites or drugs. However, proton MRS needs more sophisticated techniques for water and lipid suppression. In brain tissue, mobile lipid signals arise primarily from pericranial fat. The in vivo metabolite detection requires only water suppression using, for example, CHESS (Chemicall Shift Selective) pulses that selectively excite the tissue water signal, followed by strong dephasing gradients [20]. The spatial distributions of metabolites can be mapped with volume localization and chemical shift imaging (CSI) [21] techniques in routine clinical practice using several different methods [22-24]. Further spatial localization pulse sequences with outer volume saturation (OVS) were developed to suppress lipid signals from subcutaneous fat in the skull [25-28].

\subsection{Preclinical studies using animal tumor models of extracranial cancers}

The tissue proton spectra of most extracranial organs usually are dominated by intense water and lipid resonances that block observation of metabolites and drugs. Breast tissue represents the worst case scenario for the ${ }^{1} \mathrm{H}$ MRS observation of metabolites and drugs (Fig. 1) [29]. Roebuck and colleagues demonstrated the feasibility of ${ }^{1} \mathrm{H}$ MRS of breast cancer with choline detection using spin-echo techniques [30,31]. In vivo clinical observation of lactate, however, has been challenging in breast and other extracranial cancers. To overcome these obstacles, we have developed the Selective Multiple-Quantum Coherence transfer (Sel-MQC) methods that completely suppress lipid and water in a single scan to enable observation of metabolites and antineoplastic agents in tissues that contain high concentrations of mobile fat [32-35]. These methods have been demonstrated in simultaneous lactate and choline detection in EMT6 tumors [33] and in Iproplatin detection in RIF-1 tumors [34]. Multi-slice versions of Sel-MQC methods have been developed for 3D Sel- 
MQC mapping of metabolites. Modified Sel-MQC sequences are available to detect neuronal metabolites, glucose, Gamma-Amino Butyric Acid (GABA), and glutamate, with reduced signal overlap and excellent water suppression $[36,37]$.

\subsubsection{Lipid and water suppression in a single scan by Sel-MQC}

The Sel-MQC methods have been developed to observe proton signals of metabolites, antineoplastic agents, and unsaturated lipids in tissues with high concentrations of mobile fat. Complete suppression of lipid and water signals can be accomplished in a single scan for metabolite detection. By employing frequency-selective RF pulses, Sel-MQC methods overcome the difficulties of incomplete lipid suppression in previous multiple-quantum lactate editing methods [38]. Because a slight residual lipid signal is detrimental to the detection of metabolites in breast tissue, the robust lipid suppression offered by Sel-MQC is critical for spectroscopic imaging in breast cancer and in many extracranial cancers. The lactate spatial distribution in murine EMT6 tumors was mapped in vivo and achieved a voxel resolution of $10 \mu \mathrm{l}$ (Fig. 2.) [32]. The dispersion of the mobile lipid throughout the interior of the EMT6 tumor previously prevented in vivo lactate detection by either outer volume presaturation or long spin echo delays [39]. Due to the effectiveness of Sel-MQC in lipid suppression and its insensitivity to motion artifacts, the methods potentially are applicable to clinical detection of metabolites and drugs in human breast and other extracranial cancers.

\subsubsection{Sel-MQC-detectable lactate as an index of tumor radiosensitivity and chemotherapeutic response}

Sel-MQC was used to characterize the radiosensitivity of RIF-1 [39,40] and EMT6 tumors [41]. The radiosensitivity of these two tumor models depends on their hypoxic cell fraction (HCF). In the radiosensitive RIF-1 tumor model with low HCF, there was a significant decrease in lactate levels at $48 \mathrm{hrs}$ post-treatment following $\gamma$-radiation doses of 20,4 , and 2 Gy. For the radioresistant EMT6 tumors with high $\mathrm{HCF}$, however, the tumor showed only a $40 \%$ decrease in lactate levels at $48 \mathrm{hrs}$ following 20 Gy $\gamma$-irradiation and a $20 \%$ decrease after a 10 Gy dose. Both lactate levels and lactate dehydrogenase (LDH) activities were found to be similar in RIF-1 and EMT6 tumors. The characteristic responses of EMT6 and RIF-1 tumors thus may be explained by their different hypoxic fractions. The

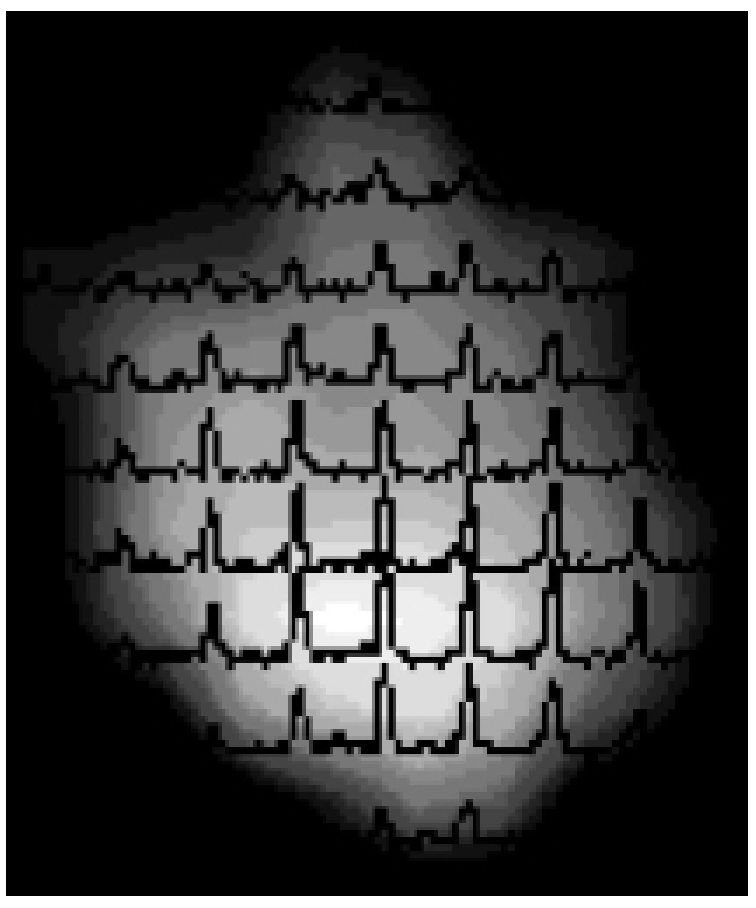

Fig. 2. An in vivo Sel-MQC lactate image obtained in 34 minutes from a $6.6 \mathrm{~mm}$ sagittal slice across an EMT6 tumor; lactate spectra from different voxels were overlaid on the image. The in-plane resolution was $1.25 \mathrm{~mm}(16 \times 16 \times 256$ points; $\mathrm{FOV}=20 \mathrm{~mm})$ [32]. (with permission).

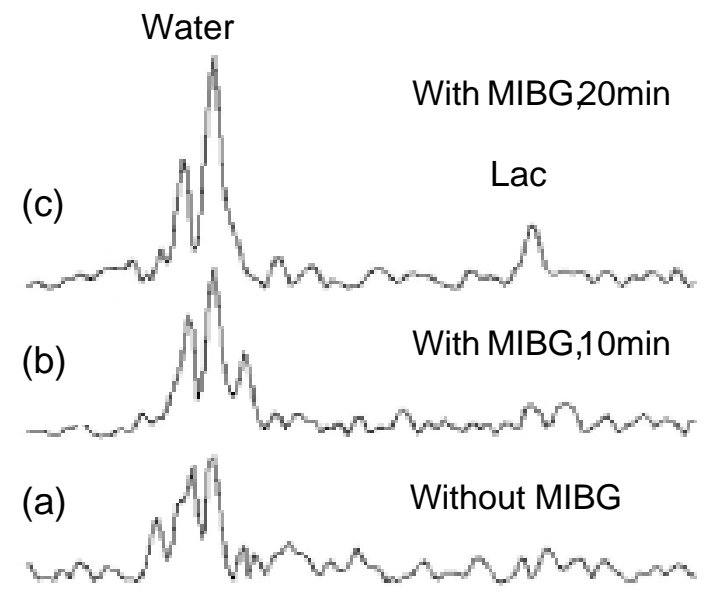

Fig. 3. High glycolysis induced in hyperglycemic human melanoma xenografts in SCID mice by reagent MIBG. (He, Gliskson, et al., unpublished data).

increase in perfusion that accompanies re-oxygenation of tumors after radiation treatment is less marked in the radioresistant model than in the radiosensitive model and may account for the less pronounced decrease in 


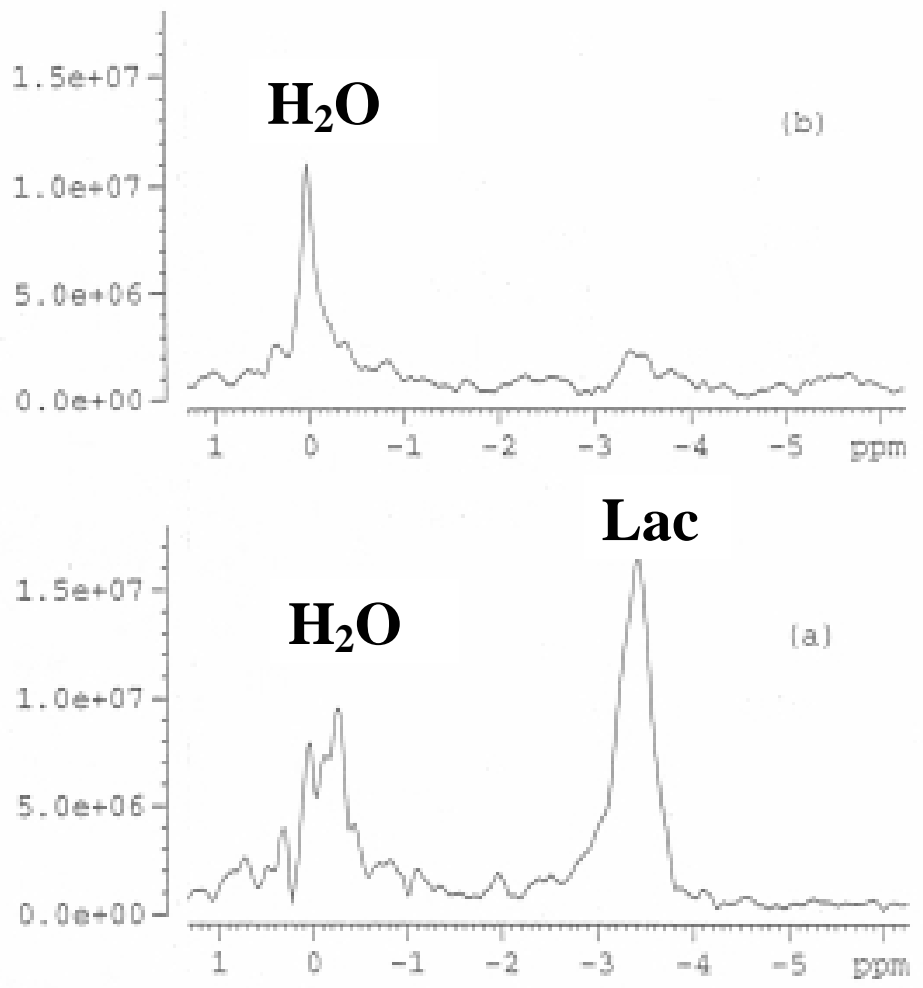

Fig. 4. In vivo lactate spectra following Salmonella administration $(5 \times 10$ i.p.) in C57 BL/6 mice acquired with 256 scans from a 5 mm slice of the Colon 38 tumor: (a) control; (b) 7 hours after injection of Salmonella. Lipid signal was completely suppressed. (Xu, He \& Pizzorno, unpublished data).

lactate levels. In EMT6 tumor models, the change in lactate levels-rather than lactate levels per se-is a useful index for radiation response.

Lactate also may be an index of early chemotherapeutic responses [42]. For example, the lactate levels in RIF-1 tumors decrease following therapeutic intervention with cyclophosphamide (Cp, $300 \mathrm{mg} / \mathrm{kg}$ ), which correlates with the increases in tumor perfusion and permeability characterized by the Gd-DTPA (Gadolinium diethylenetriaminepentaacetic acid) uptake curves. The decrease in lactate levels may be due to the increased perfusion and tumor re-oxygenation. Compared to the control tumors, tumor volumes decreased significantly in the cyclophosphamide-treated animals. In addition, the GPC/PC ratio was higher in the treated tumors (GPC-Glycerophosphocholine; PCphosphocholine).

\subsubsection{Induced lactate elevation and selective acidification of tumor tissues}

Animal tumors and human cancers may not display elevated lactate. The lactate levels in various human cancers reflect their glycolytic capacities and blood flow characteristics. Inhibition of oxidative phosphorylation to induce glycolysis and increase the lactate export to extracellular space in tumors may aid in MRSI diagnosis and therapeutic cancer interventions by selective tumor acidification [43]. In a Sel-MQC experiment carried out on an SMIS 4.7T animal spectrometer on human melanoma xenografts, we enhanced the tumor glycolytic pathway by intraperitoneal (i.p.) injection of meta-iodobenzylguanidine (MIBG) under hyperglycemic conditions (Fig. 3). Lactate was absent in the control Sel-MQC experiment before injection of MIBG (Fig. 3a). Lipid signals that overlap with lactate signals were suppressed completely. Zhou et al. showed in a later, more systematic study that, in small tumors of human melanoma xenografts, the combination of hyperglycemia and MIBG (30 mg/kg) decreased the intra- and extracellular $\mathrm{pH}$ levels by 0.4 and 0.6 , respectively; and lowered the $\beta$-nucleoside triphosphate (NTP)/inorganic phosphate $(\mathrm{Pi})$ ratio of tumor and liver by about $60 \%$ and $25 \%$, respectively [44]. Further selective acidification of tumors and sensitization to hyperthermal therapy were achieved by blocking the lactate/ $\mathrm{H}^{+}$symporter with $\alpha$-cyano-4- 


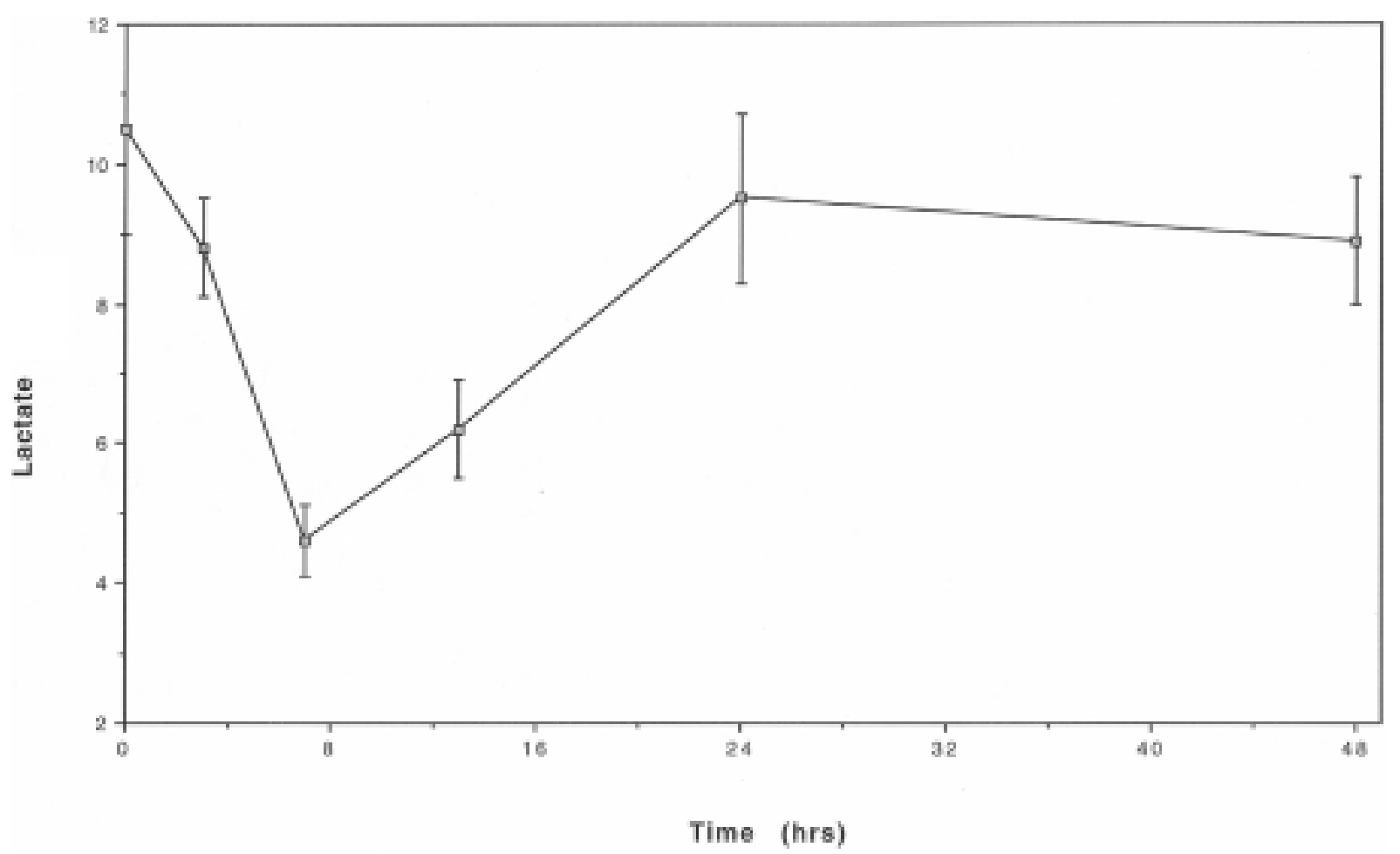

Fig. 5. The time course of lactate levels in Colon 38 tumors following Salmonella administration detected using Sel-MQC. (Xu, He \& Pizzorno, unpublished data).

hydroxycinnamate $(\mathrm{CNCn}, 300 \mathrm{mg} / \mathrm{kg})$ and lonidamine $(100 \mathrm{mg} / \mathrm{kg})$, or the $\mathrm{Na}^{+} / \mathrm{H}^{+}$symporter with cariporide (HOE642, $160 \mathrm{mg} / \mathrm{kg}$ ) and $\mathrm{Cl}^{-} / \mathrm{HCO}_{3}^{-}$symporter with 4,4'-diisothiocyanatostilbene-2, $2^{\prime}$-disulfonic acid (DIDS, $50 \mathrm{mg} / \mathrm{kg}$ ). In general, human melanoma is poorly responsive to radiation therapy and most forms of chemotherapy. Selective acidification of human melanoma may be a useful way to enhance hyperthermic therapy in clinies [44].

\subsubsection{In vivo ${ }^{1} H$ MRS detection of the antineoplastic agent Iproplatin in RIF-1 tumors}

Proton detection of drugs in vivo, although highly desirable, has not been very successful in the past for two reasons-low tissue drug concentration and overlapping of drug signals with resonances of metabolites, lipids, or water. To circumvent problems with background signals, ${ }^{19}$ F NMR has been used widely to study pharmacokinetics in tissues [46]. This approach, however, often requires chemical modification of the pharmacological agents. With Sel-MQC, we observed in vivo the proton MR spectrum of a drug [34]. Iproplatin, an antineoplastic agent that cross-links nucleotides in both single and double strand DNA molecules and used in breast cancer therapy [47], was detected selectively in the RIF-1 murine tumor models. The overlapping lactate methyl proton signals and lipid signals were removed by the MQ-selection gradients using the SelMQC sequence [34].

\subsubsection{Tumor-specific accumulation of Salmonella bacteria using lactate as a nutrient carbon source}

The bacteria-based therapies initiated 50 years ago for the clinical management of cancer generated an astonishing record that a small fraction $(\sim 10 \%)$ of patients were cured by the bacteria-based therapy [48]. These earlier clinical investigations were stopped because of the occurrence of systemic infections. The virulence of the Salmonella can be reduced by genetic engineering approaches as shown recently by Pawelek et al. [49]. An attenuated Salmonella typhimurium that possesses high tropism for tumor tissues recently has been introduced in clinical trials [49-51]. New Salmonella strains (e.g., YS72) not only have much reduced virulence but also penetrate into the hypoxic and necrotic areas of tumor tissue and accumulate in many tumor types, including distance metastasis, about 


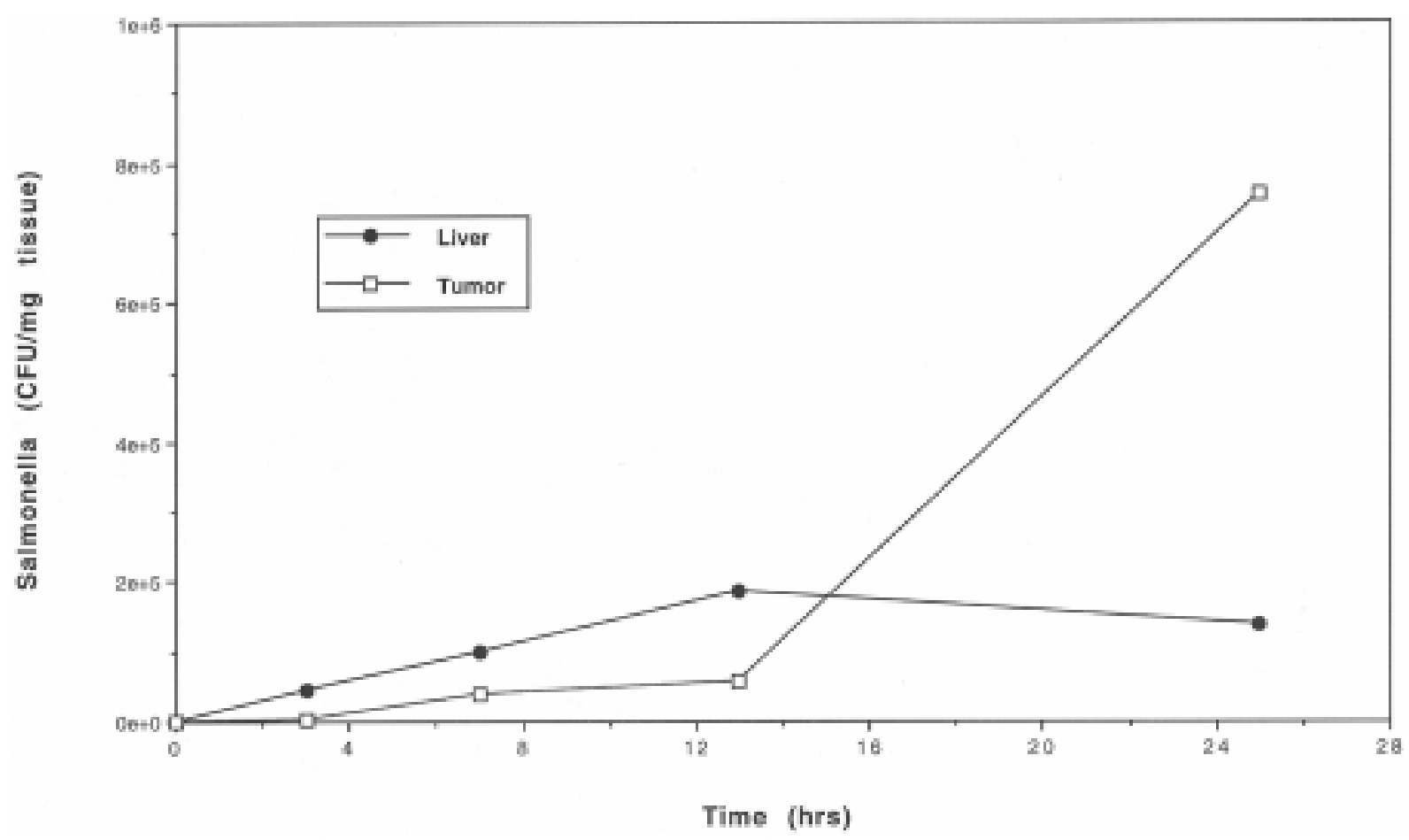

Fig. 6. The time course of Salmonella amplification in tumors as compared to its growth in the liver of the same animal. (Xu, He \& Pizzorno, unpublished data).

9,000-fold greater than in liver or other normal tissues. The new bacteria have shown cytotoxic effects in tumor cells [49] and have been shown to be a gene-delivery vehicle with inherent tumor specificity [50,52]. Most of the new Salmonella strains remain in the extracellular space, but a few can penetrate into the cytoplasm of tumor cells.

We studied the mechanisms of the tumor-specific replication effect of attenuated Salmonella typhimurium in a murine Colon 38 tumor model [53]. We found that, 7-8 hours after intraperitoneal administration of the Salmonella, there was a rapid reduction in the lactate level (80\%) (Fig. 4). This was followed by a fast recovery to the pre-treatment level within 24 hours of the initial infection (Fig. 5), when the bacteria reach maximum replication (Fig. 6) [53]. This indicates that the selective advantage and replication of the attenuated Salmonella typhimurium in tumor tissues may be caused in part by the elevated lactate [7,54], which serves as a nutrient carbon source in the initial phase of the selective bacterial replication in tumor tissues. Because the attenuated Salmonella accumulates in many types of tumors and metastatic lesions, research is in progress in our laboratory using the new Salmonella strain as an imaging and therapeutic agent to detect local and metastatic tumors [55]. In 2001, Vogelstein and co-workers showed that bacteria were capable of killing hypoxic tumor cells [56] that escaped most radiation- and chemotherapies [57]. They reported that the combination of the bacterial therapy targeted against hypoxic tumor cells and a conventional therapy targeted against well-oxygenated tumor tissues completely eliminated the tumors in animal models [56].

\subsubsection{Spin-echo enhanced Sel-MQC-Observation of multiple metabolites with lipid and water suppression in a single scan}

Like other lactate editing methods, Sel-MQC measures only one metabolite or drug at a time, which is inefficient for monitoring metabolic or pharmacological changes. Since Sel-MQC excites only resonances in the lactate $\mathrm{C} \bar{H}(4.1 \mathrm{ppm})$ and $\mathrm{C} \bar{H}_{3}(1.3 \mathrm{ppm})$ regions of the spectrum, the z-magnetization of metabolite signals outside these ranges remains intact; therefore, the signals of other metabolites can be detected by additional frequency-selective pulses. We developed a spin-echo enhanced Sel-MQC (SEE-SelMQC) sequence in which a selective spin-echo component was added to the Sel-MQC sequence to recover signals from metabolites other than lactate. This sequence 


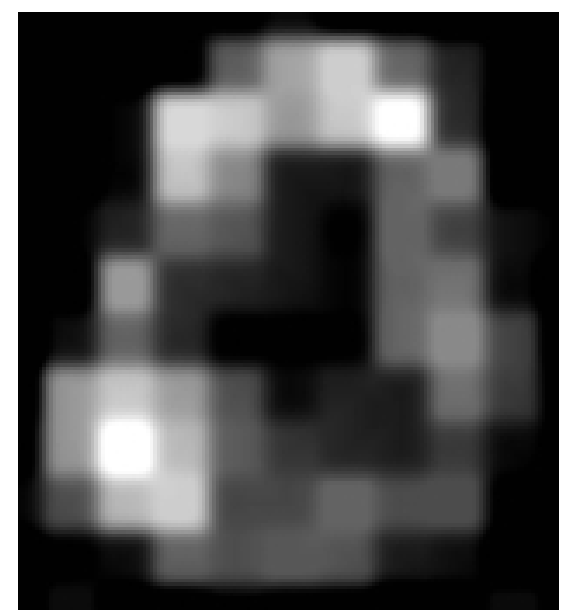

(a)

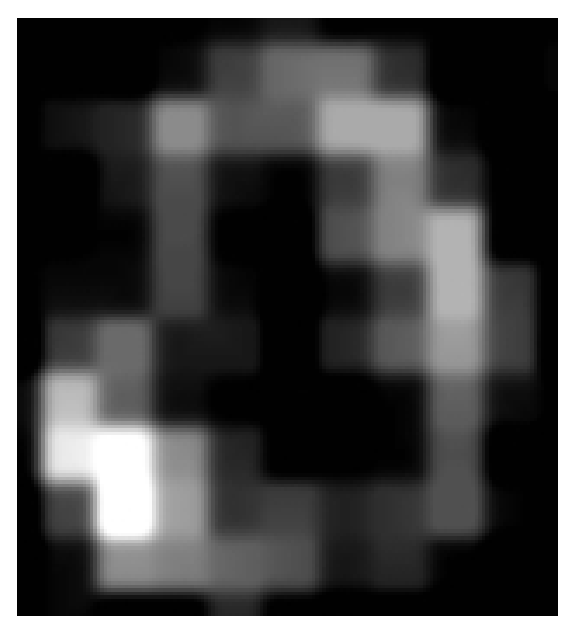

(b)

Fig. 7. The choline (a) and lactate (b) spatial distributions were mapped in a subcutaneously implanted EMT6 tumor using the SEE-SelMQC sequence. The images were obtained from a $9.6 \mathrm{~nm}$ sagittal slice of the tumor, with 16 phase-encoding steps in two dimensions for a field of view of $25 \mathrm{~mm}$ (Voxel size $=23.4 \mu \mathrm{l})$ [33] (with permission).

detects signals from multiple metabolites in a single scan with complete lipid and water suppression and is, therefore, insensitive to motion artifacts. With the SEE-SelMQC CSI sequence, choline (Fig. 7a) and lactate (Fig. 7b) simultaneously were mapped in vivo in the murine EMT6 tumor model. The images were obtained from a $9.6 \mathrm{~mm}$ sagittal slice of the tumor, with 16 phase-encoding steps in two dimensions for a field of view of $25 \mathrm{~mm}$ [33]. Other variation sequences of SEE-SelMQC also are available for the in vivo MRS detection of multiple metabolites [58].

\subsubsection{Quantification of metabolite concentrations in biological tissues}

An attribute of in vivo MRS is its potential to quantitatively determine metabolite concentrations in living tissues. However, an MRSI experiment measures only relative concentrations of metabolites, with signal intensity weighted by their spin $T_{1}$ and $T_{2}$ relaxation times and the RF field distribution in the coil. In most MRS studies, when prior knowledge of the internal reference is available, metabolite ratios are chosen to express their concentrations in biological tissues [59]. For example, the creatine peak that is assumed to remain constant in the human brain frequently has served as an internal reference for the tissue concentration of brain metabolites in MRS. In pathological conditions, the assumption that the internal reference maintains a constant concentration may not be valid. Therefore, the methods for quantifying metabolite concentrations using internal references may not be accurate. This issue has been addressed by several methods that employ an external refernerence signal from phantoms that contain a chemical of known concentration to calibrate tissue metabolite levels [60-62]. Signal decays due to spin $T_{1}$ and $T_{2}$ relaxations and $B_{1}$ inhomogeneity must be calibrated. To use the external reference approach for absolute quantification of metabolite signals detected by Sel-MQC, we developed the $\mathrm{T}_{1}$ - and $\mathrm{T}_{2}$ SelMQC sequences to measure lactate relaxation rates in breast tissue and in animal tumor models [63]. When combined with appropriate RF field calibration procedures, quantitative determination of metabolite concentrations in extracranial cancers is feasible [61].

\subsection{In vivo characterization of tumor metabolic rates by isotope labeled glucose infusion}

The in vivo magnetic resonance measurements of lactate level, ${ }^{13} \mathrm{C}$-labeled glucose uptake and glycolytic rate, and blood perfusion in tumor tissues of animal tumor models and spontaneous human cancers reflect the physiochemical states of the up-regulation of glucose transporters, glycolytic enzymes, HIF-1 recruited tumor angiogenesis, and tumor cell $\mathrm{pH}$ regulation, all of which are related to tumor progression and malignancy [64]. The glycolytic capacity of tumors as measured by lactate production, when normalized for $\mathrm{O}_{2}$ availability, is proportional to the tumor growth rate. High lactate production in fast-growing tumors results from reduced mitochondrial oxidative activity relative 


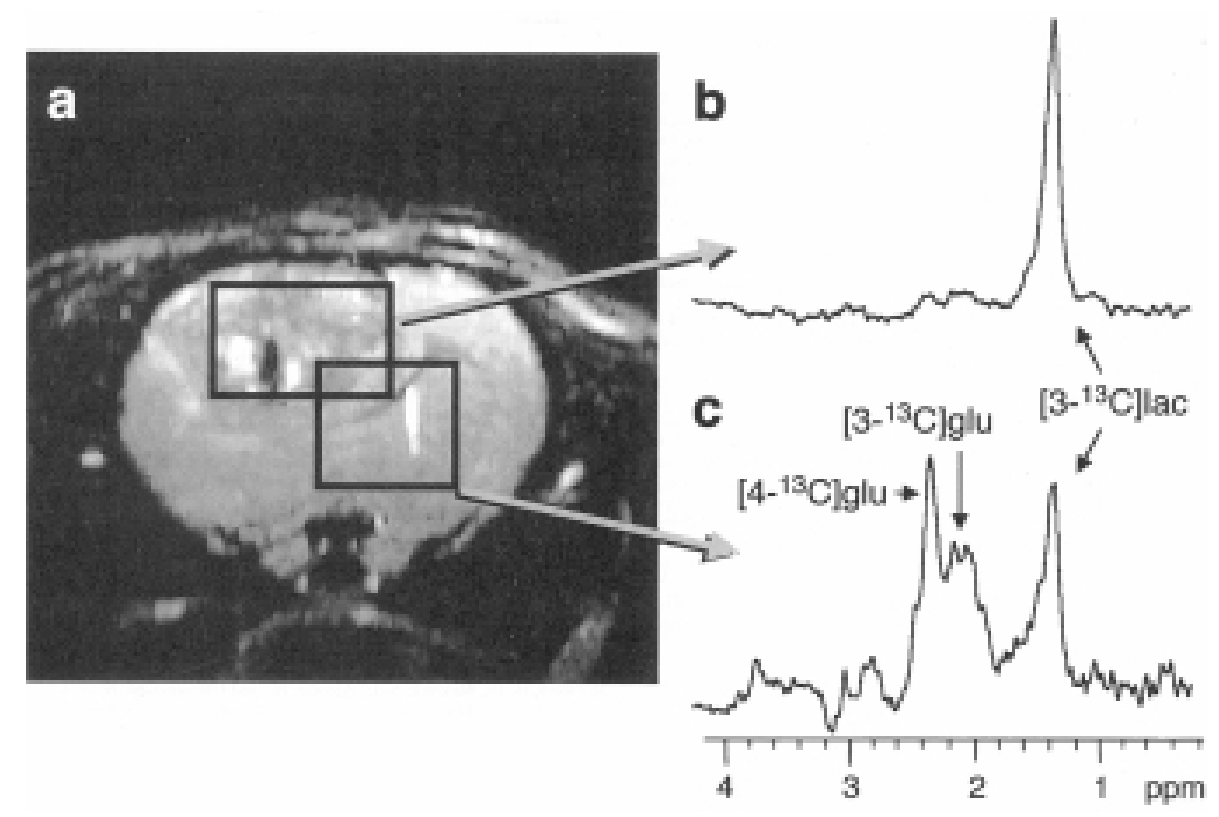

Fig. 8. (a) $\mathrm{T}_{2}$-weighted image of a representative $\mathrm{C} 6$ glioma (coronal view). Rectangles outline the voxels chosen to represent tumor and contralateral hemisphere for the spectroscopic measurements of ${ }^{-13} \mathrm{C}$-labeled cerebral metabolites glutamate (glu) and lactate (lac). (b) Spectrum from the tumor voxel acquired between $\mathrm{h} 4$ and 5. (c) Spectrum from the voxel in the normal healthy contralateral hemisphere acquired between $3 \mathrm{~h}$ and $4 \mathrm{~h}$ of continuous $\left[1^{-13} \mathrm{C}\right]$ glucose infusion [69]. (with permission).

to glycolytic capacity to utilize pyruvate. Most rapidly growing tumor cells have the capacity to use much more glucose than their tissue of origin.

It is important to appreciate, however, that even in rapidly growing tumor cells in culture, mitochondrial oxidative phosphorylation still accounts for the major source of ATP. Cells grown on alternative carbohydrate sources, which bypass the hexokinase step, produce much less lactate than cells grown on glucose. Cells grown on glucose in culture may obtain, at most, $50 \%$ of their ATP from glycolysis, whereas cells grown on other carbohydrate sources probably derive less than $10-20 \%$ of their ATP from glycolysis and as much as $90 \%$ from mitochondrial oxidative phosphorylation in the presence of $20 \%$ oxygen. Glycolytic rates can be measured in ${ }^{13} \mathrm{C}$ MRS experiments in vitro in cells or cell spheroids and in vivo in animal tumor models and human xenografts by following the uptake and metabolism of the ${ }^{13} \mathrm{C}$-labeled glucose. High rates of glucose consumption and lactate production have been observed by ${ }^{13} \mathrm{C}$ NMR in mammary MCF7 and T47D tumor cells and spheroids [65]. Glycolytic rates as high as $80 \%$ of the glucose being metabolized to lactate were detected in MCF7 cells. A decrease in overall energy production due to increased glycolysis was also observed during the growth of T47D cell spheroids.
Tumors in vivo utilize much more glucose than do tumor cells in culture and produce a large amount of lactic acid. In contrast to cultured cells, cells in solid tumors are exposed to hypoxia, and their mitochondrial oxidative phosphorylation is significantly slowed due to the oxygen requirements of mitochondrial respiratory functions [66]. Three-dimensional tumor growth, therefore, relies on glycolysis. Glycolysis may be more important in supplying the source of ATP for tumor cells in vivo than in vitro at least to the hypoxic fraction $[67,68]$. The relative importance of glycolysis to mitochondrial oxidative phosphorylation in tumors needs to be studied further in animal tumor models and in human cancers.

The kinetics of ${ }^{13} \mathrm{C}$-glucose metabolism in $\mathrm{C} 6$ glioma and the contralateral brain hemisphere were measured to determine the glycolytic flux rate (Fig. 8) [69], using a pulse sequence [70] to measure the ${ }^{13} \mathrm{C}$-labeled compounds and an editing sequence employing adiabatic pulses to measure the total pool of lactate [71]. The kinetic model assumes a rapid consumption of glucose in glycolysis, whereas lactate is a metabolic end product that is removed from the cell by facilitated transport followed by a rapid elimination from the vascular capillaries. As expected, the tumor C6 gliomas have a much higher glycolytic rate $\left(0.043 \pm 0.007 \mathrm{~min}^{-1}\right)$, as determined from the time 

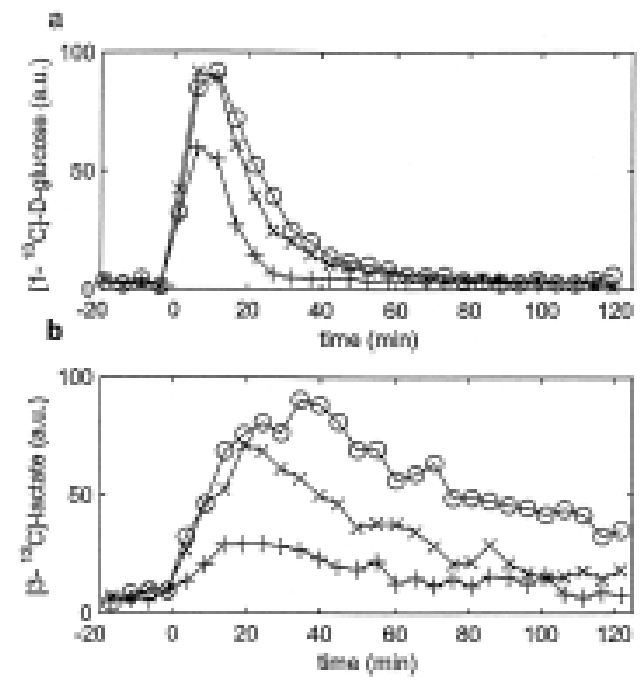

(A)

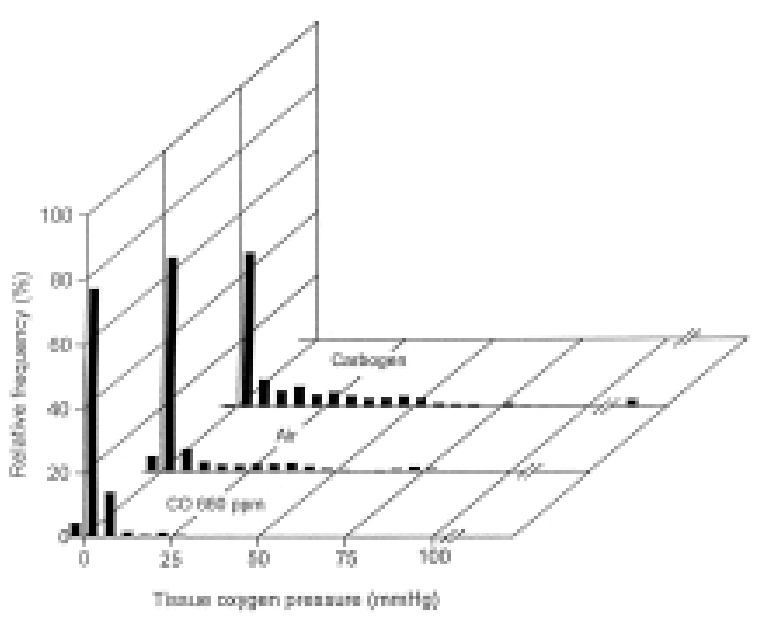

(B)

Fig. 9. (A) Time course evolution of the population mean amplitude for ${ }^{13} \mathrm{C}$ labeled (a) glucose and (b) lactate from a simplified two-compartment model for tumor glycolytic rate determination. $\bigcirc=$ animals breathing air containing $\operatorname{CO}_{660} \operatorname{ppm}(n=6) ; \times=$ animals breathing atmospheric air; $+=$ animals breathing carbogen $(n=6)$. (B) Pooled histogram showing oxygenation profiles obtained in the $\mathrm{C} 3 \mathrm{H}$ tumor implanted on the backs of mice under normal air-breathing conditions and when mice breathed carbogen or $\mathrm{CO}_{660} \mathrm{ppm}$ [73]. (with permission).

course of the elevated ${ }^{13} \mathrm{C}$-lactate synthesis (Fig. $8 \mathrm{~b}$ ), than the normal brain parenchyma that employ oxidative metabolism as measured by ${ }^{13} \mathrm{C}$-labeled glutamate after the TCA cycle of the infused ${ }^{13} \mathrm{C}$ label (Fig. 8c).

Using a two-compartment model that assumes lactate is the end product, Artemov and colleagues determined the average rate of glycolysis and the rate of lactate clearance through the vasculature of radiationinduced fibrosarcoma (RIF-1) tumors as $0.022 \pm 0.01$ and $0.034 \pm 0.006 \mathrm{~min}^{-1}$, respectively [72]. A direct ${ }^{13} \mathrm{C}$ detection technique was used with signal enhancement from ${ }^{1} \mathrm{H}$ by selective Hartman-Hahn crosspolarization transfer. A more complicated model should be used if the tumor has a detectable glutamate/glutamine pool for measuring TCA cycle activity. This two-compartment model was used subsequently by Nielsen and colleagues to assess glycolytic metabolism of murine $\mathrm{C} 3 \mathrm{H}$ mammary carcinoma affected by different conditions of tumor oxygenation (Fig. 9) [73]. Under conditions of acute hypoxia induced by breathing carbon monoxide at $660 \mathrm{ppm}$, the apparent glycolytic rate was $0.0239 \pm 0.0019 \mathrm{~min}^{-1}$, with a 25 -fold lower incorporation of ${ }^{13} \mathrm{C}$ label into $\left[4-{ }^{13} \mathrm{C}\right]$ glutamate. Lower glycolytic rates were calculated as $0.0160 \pm 0.0021 \mathrm{~min}^{-1}$ and $0.0050 \pm$ $0.0011 \mathrm{~min}^{-1}$, respectively, for animals breathing air or carbogen $\left(95 \% \mathrm{O}_{2}+5 \% \mathrm{CO}_{2}\right)$. The incorporation rate of the ${ }^{13} \mathrm{C}$ label into glutamate still was lower than that of labeled lactate (11-fold for air and 9-fold for carbogen, respectively), but slightly greater oxidative metabolism was detected than in animals breathing $\mathrm{CO}$ at $660 \mathrm{ppm}$. The calculated values of glycolytic rate under well-oxygenated conditions introduce relatively larger systematic errors because the kinetic model assumes dominant glycolysis, leading to an underestimate of pyruvate oxidized by the tumor mitochondria. Thereby, the combined measurement of glycolysis and oxidative metabolism would provide more information regarding tumor energy status than would the measurement of glycolysis alone, due to the heterogeneity of the tumor blood flow and perfusion properties. A more complex mathematical model was adapted to measure the metabolic flux of a perfused rat heart [74-76]. In this tumor model, no reduction of tumor $\mathrm{pH}$ was observed as the glycolytic rate increased. When they compared this data with blood flow measurements from the same animal model, the investigators concluded that the $\mathrm{C} 3 \mathrm{H}$ mammary carcinoma is capable of maintaining tumor energetic status despite a reduction in tumor blood perfusion of 80-90\%.

To compare the relation between glycolytic lactate production and tumor growth rate in different tumor cells, it is important to normalize the lactate-producing capability for tissue $\mathrm{O}_{2}$ level if it can be measured independently. Note that a high lactate tissue concentration does not always correspond to a high glycolytic rate. For example, Petroff and colleagues showed that lactate could be trapped in metabolically isolated com- 
partments with persistently impaired perfusion, as in human brain tissue with low metabolic activity after stroke. Macrophages that infiltrate necrotic areas are partially responsible for the production of lactate in normoxic conditions [77]. Therefore, it would be advantageous to characterize tumor energy status by combined measurements of ${ }^{1} \mathrm{H}$ MRSI for the total lactate pool and ${ }^{13} \mathrm{C}$ MRS for glycolytic rates, with tissue oxygenation measured by perfusion measurements [78,79]. Rapidly growing malignant tumors have high glycolytic phenotypes due to both the hypoxic tumor microenvironment and genetic changes in the malignant cells. For benign tumors with low growth rates, lactate levels may stay low. Therefore, ${ }^{1} \mathrm{H}$ detection of lactate and ${ }^{13} \mathrm{C}$ measurement of tumor glycolytic rates normalized for tissue oxygen levels may be used to differentiate malignant lesions from benign lesions and normal cells from fibrosis. These differentiations may not be resolved by contrast-enhanced MRI and other methods.

(See the Chapter by Collier et al., in Functional Imaging of Early Markers of Disease. Part 1 [80] for a discussion of FDG-PET measurement of tumor glucose uptake.)

\section{MR characterization of tumor microenvironments-Neovascular permeability, tumor oxygenation, tissue protein distributions, and metastatic potential}

Advances in non-invasive molecular imaging techniques, including MRS, provide a unique opportunity for studying tumor microenvironments such as tumor blood flow, oxygenation, and hypoxia. Malignant cells secrete growth factors that stimulate the development of highly irregular, tortuous blood vessels with blind ends, arterio-venous shunts, lack of smooth muscle, endothelial linings, and basement membranes. These often produce heterogeneous and sluggish blood flow. Rapidly proliferating tumor cells may grow away from vessels, beyond the effective diffusion distance of oxygen $(>150 \mu \mathrm{m})$, which causes regional hypoxia and necrosis. Hypoxic tumor cells have different genetic characteristics (e.g., different levels of p53 expression) and apoptotic processes. Such cells may be more invasive and may be resistant to conventional systemic anticancer therapies than non-hypoxic tumor cells.

\subsection{Tumor microenvironments and metabolic phenotyping by $M R S$}

Recent studies of dynamic contrast-enhanced MRI using macromolecular contrast agents revealed an interesting facet of tumor neovasculature. Tumor regions of high permeability often are associated with hypoxia and necrosis and frequently display lower vascular volumes (Fig. 10) [81,82]. In vivo $\mathrm{pH}$ measurement using endogenous inorganic phosphate by ${ }^{31} \mathrm{P}$ MRS revealed a neutral or alkaline tumor intracellular $\mathrm{pH}$; the extracellular $\mathrm{pH}$ of tumors is acidic relative to normal tissue and can be measured by extraneous agents, such as ( \pm 2-imidazole-1-yl-3-ethoxycarbonylpropionic acid (IEPA) or 3-aminopropyl phosphonate (3-APP) [8183]. Tumor extracellular $\mathrm{pH}$ becomes more acidic with tumor growth and increased metastatic potential. Bhujwalla and colleagues showed that the overexpression of metastasis suppressor gene nm23 increases tumor extracellular $\mathrm{pH}$ and reduces intracellular $\mathrm{pH}$ [84]. The difference in tumor microenvironments is coupled with tumor genetic and metabolic changes that can be detected by MRS. For example, a "GPC to PC switch," which is associated with altered choline phospholipid metabolism in mammary epithelial cells, was observed as an early phenotypic change during tumor progression [85]. The transfection of $\mathrm{nm} 23$ in the MDA-MB-435 human breast cancer cells altered tumor phospholipid metabolism and $\mathrm{pH}$, suggesting possible mechanisms of phospholipid-mediated signaling for cell motility change as well as altered $\mathrm{pH}$-stimulated cell invasion and metastasis [84]. Treating malignant cells with indomethacin that reduced the malignant behavior of human breast cancer cells altered the "malignant phospholipid phenotype" (which was characterized by high PC/GPC and high total choline) toward the "non-malignant phospholipid phenotype [86,87]."

\subsection{Tumor tissue oxygenation and hypoxia}

Tumor hypoxia is an important factor leading to resistance to radiation therapy that relies on the cellular oxygenation level to be effective. Most human solid tumors have median $\mathrm{pO}_{2}$ levels that are lower than those of their tissues of origin $(<10 \mathrm{mmHg})$. Therefore, in vivo measurements of tumor oxygen distribution provide a critical parameter of tumor physiological microenvironments when selecting a therapeutic strategy. Tissue oxygen measurements can be classified into two categories-direct measurement using electrochemical reactions of oxygen molecules or indirect measure- 


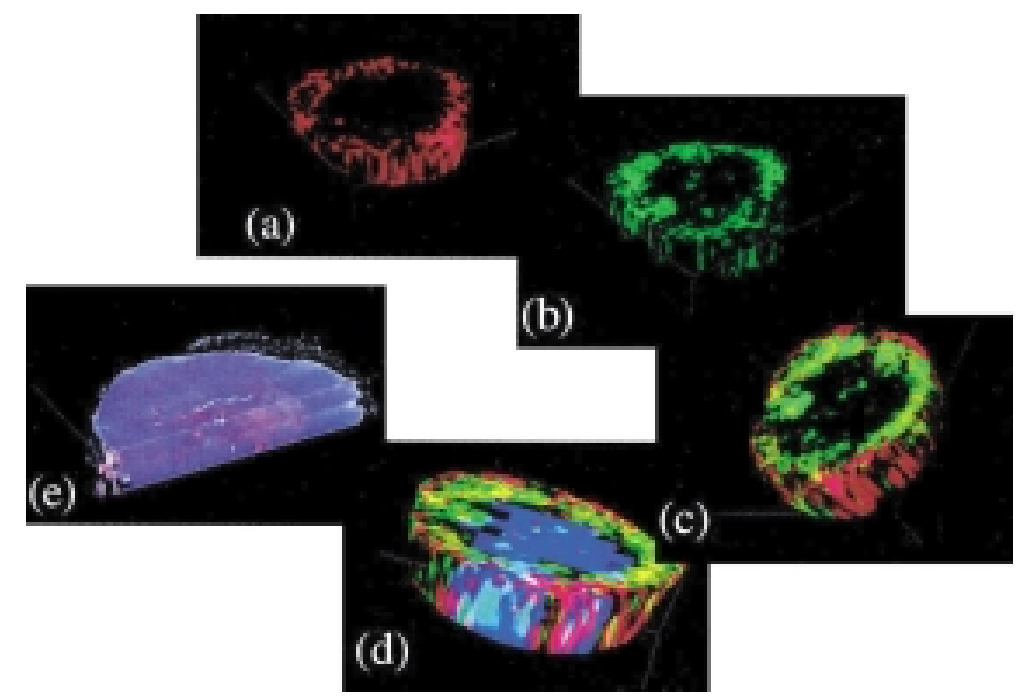

Fig. 10. Co-registration of vascular volume, permeability, and extracellular $\mathrm{pH}$, measured with IEPA. 3D reconstructed maps obtained from a single MDA-MB-231 tumor $\left(460 \mathrm{~mm}^{3}\right.$ ) of (a) an MRI map of vascular volume (range 0-200 $\mu \mathrm{l} / \mathrm{g}$ ); (b) an MRI map of vascular permeability (range 0-7 $\mu \mathrm{l} / \mathrm{g}$-minute); (c) a fused map of vascular volume and permeability; (d) a fused map of vascular volume, permeability, and $\mathrm{pH}$ (range 5.3-7.2); and (e) hematoxylin and eosin-stained histological sections. Spatial resolution of the vascular volume and permeability maps is $0.125 \mathrm{~mm}$ in-plane with $1-\mathrm{mm}$ slice thickness. The $\mathrm{pH}$ map was obtained with a spatial resolution of $1 \mathrm{~mm} \times 1 \mathrm{~mm} \times 4 \mathrm{~mm}$ [159]. (with permission).

ment using reporter molecules, such as luminescent molecules whose emissions can be quenched by $\mathrm{O}_{2}$ and myoglobin or other $\mathrm{O}_{2}$-sensitive proteins that bind to $\mathrm{O}_{2}$ in a quantifiable manner. Tissue oxygen tension can be obtained by MRS measurement of deoxy- and oxymyoglobin signals [88-94], or by Near InfraRed (NIR) spectroscopy using oxy-and deoxy-hemoglobin, which absorb NIR light [95]. Mitochondrial redox imaging was developed to measure the relative local redox ratio of nicotinamide-adenosine dinucleotide in its reduced form from the fluorescence signal of the intrinsic fluorochromes, the reduced nicotinamide-adenosine dinucleotide and flavoproteins [96,97]. Recent advances in diffuse optical tomography (DOT) provide sufficient penetration depth for imaging the oxygen saturation of tumors $[98,99]$. However, DOT depends on vasculature to measure tissue oxygenation and diffuse diffracted light has resolution limitations when quantifying hypoxia or necrotic areas in tumors.

\subsection{1. $\mathrm{pO}_{2}$ mapping by ${ }^{19} \mathrm{~F}-\mathrm{MRS}$ using perfluorocarbon}

Perfluorocarbon (PFC) emulsions have been used to measure oxygen tension using Fluorine-19-NMR spectroscopy (Fig. 11) [81,100]. PFC particles can pass through "leaky" tumor vascular walls and accumulate in interstitial space. The NMR spin-lattice relaxation rate of the PFC, $R_{1}\left(1 / T_{1}\right)$, is enhanced by dissolved molecular oxygen as a function of $\mathrm{O}_{2}$ concentration. Consequently, $\mathrm{R}_{1}$ of the PFC can be a sensitive indicator of tumor oxygen tension in vivo. The delivery of PFCs, which depends on tumor blood flow, limits applications in mapping oxygenation in hypoxic and necrotic areas.

\subsubsection{In vivo MRS mapping of the tissue oxygen reporter myoglobin}

The myoglobin measurement using MRS is the most direct and accurate method for tissue $\mathrm{pO}_{2}$ mapping that is independent of blood flow. In principle, any $\mathrm{O}_{2}$-sensing protein can be used to measure tissue oxygen tension if a quantitative relationship exists between the protein concentration and oxygen tension. Indeed, the oxygen dissociation curves of myoglobin and hemoglobin are well-known. The oxygen dissociation curve of myoglobin is hyperbolic, whereas that of hemoglobin is sigmoidal (Fig. 12). Myoglobin has a higher affinity for oxygen than hemoglobin at lower $\mathrm{pO}_{2}$. From the oxygen to myoglobin binding equilibrium, oxygen tension can be measured by the fractional occupancy $(\mathrm{Y})$ of all the oxygen-binding sites of Mb. MRS can detect either deoxy-myoglobin or oxy-myoglobin, which can be used to calculate $\mathrm{pO}_{2}$ values.

The myoglobin has a distinctive resonance in MR spectrum at (-79.8 ppm associated with deoxy- 


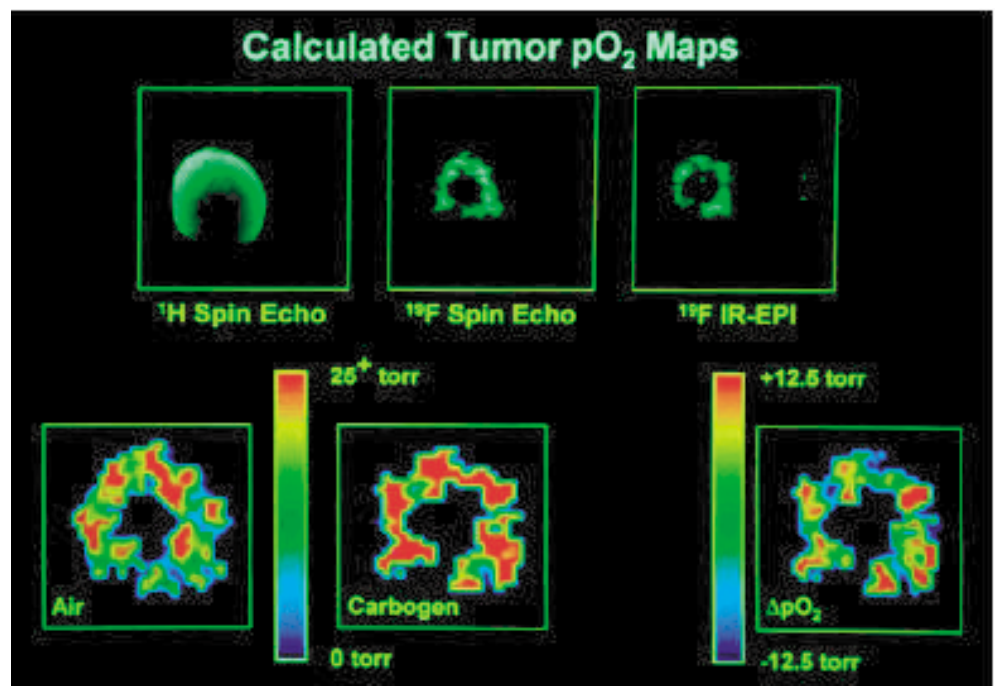

Fig. 11. Oxygen-tension mapping in a radiation-induced fibrosarcoma (RIF-1) tumor implanted on the lower back of a C3H mouse that received a $10 \mathrm{~g} / \mathrm{kg}$ dose of perfluoro-15-crown-5-ether 4 days before imaging at 2.0T. Upper left: Coronal ${ }^{1} \mathrm{H}$ spin-echo image of RIF-1 tumor. Upper center: Coronal projection ${ }^{19} \mathrm{~F}$ spin-echo image of sequestered perfluoro-15-crown-5-ether in the same tumor; Coronal projection ${ }^{19} \mathrm{~F}$-invasion recovery-EPI of the same tumor. Lower left and center: Calculated $\mathrm{pO}_{2}$ map for animals breathing air and carbogen, respectively. The bar indicates $\mathrm{pO}_{2}$ values from 0 to $>25$ Torr. Lower right: Difference in $\mathrm{pO}_{2}$ map obtained by subtracting $\mathrm{pO}_{2}$ map on the lower left from the lower center (Carbogen-Air). Color scale now indicates change in $\mathrm{pO}_{2}$ from -12.5 to +12.5 Torr [81]. (with permission).

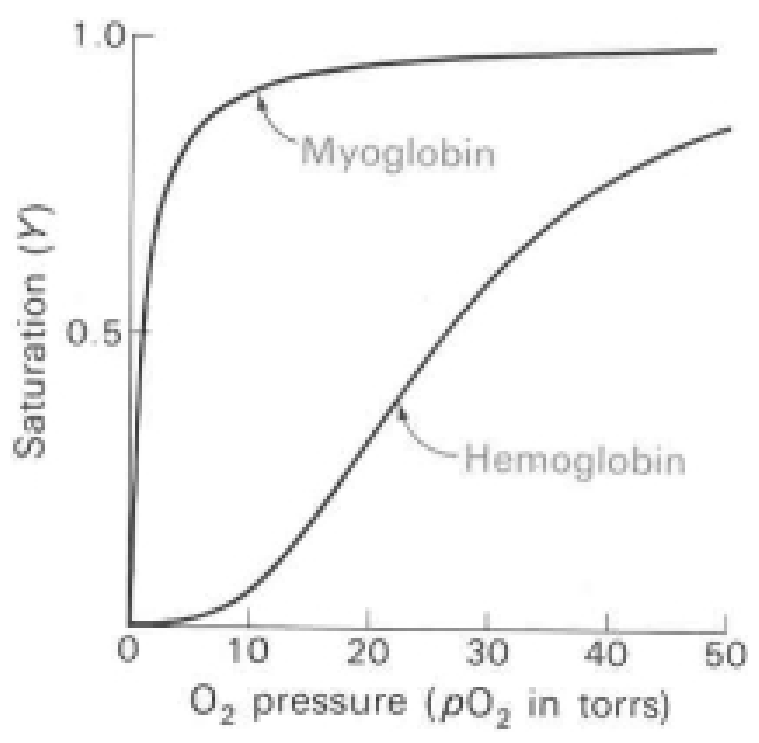

Fig. 12. Oxygen dissociation curves of myoglobin and hemoglobin. Saturation of the oxygen-binding sites is plotted as a function of the partial pressure of oxygen surrounding the solution [160]. (with permission).

myoglobin resonance, which has been detected in human muscle and the myocardium of animals and human (Fig. 13) [91-94,101-103]. The methyl group of Val-E11 resonance at $(-2.76 \mathrm{ppm}$ is associated with oxymyoglobin [91]. Both resonances are sensitive to changes in cellular oxygen level, yet the $(-79.8 \mathrm{ppm}$ resonance is more convenient to use because it is far away from other peaks. Although deoxy-Mb is a sensitive and accurate $\mathrm{O}_{2}$ probe for non-invasive MR characterization of tissue oxygen tension, tumor cells in general do not express MR-detectable myoglobin. Many attempts to overexpress myoglobin in tumor cells by standard methods have failed to achieve a high-level protein expression. We are in the process of developing an alternative approach to express the cDNA of myoglobin in the attenuated Salmonella typhimurium, which accumulates in tumor tissues, to map tumor oxygenation.

\section{Metabolic markers in clinical cancer diagnosis by MRSI}

\subsection{MRSI of human breast cancer}

\subsubsection{MRS-detectable choline elevation improves the diagnostic specificity of breast cancer}

Benign and malignant breast lesions can be differentiated by ex vivo proton MRS using fine-needle aspiration biopsy (FNAB). The ratio of resonances at 3.25 ppm from choline-containing metabolites to the signal at $3.05 \mathrm{ppm}$ from creatine and phosphocreatine serves as an index with a sensitivity and specificity of $95 \%$ and $96 \%$, respectively [104]. Due to the low cellular den- 

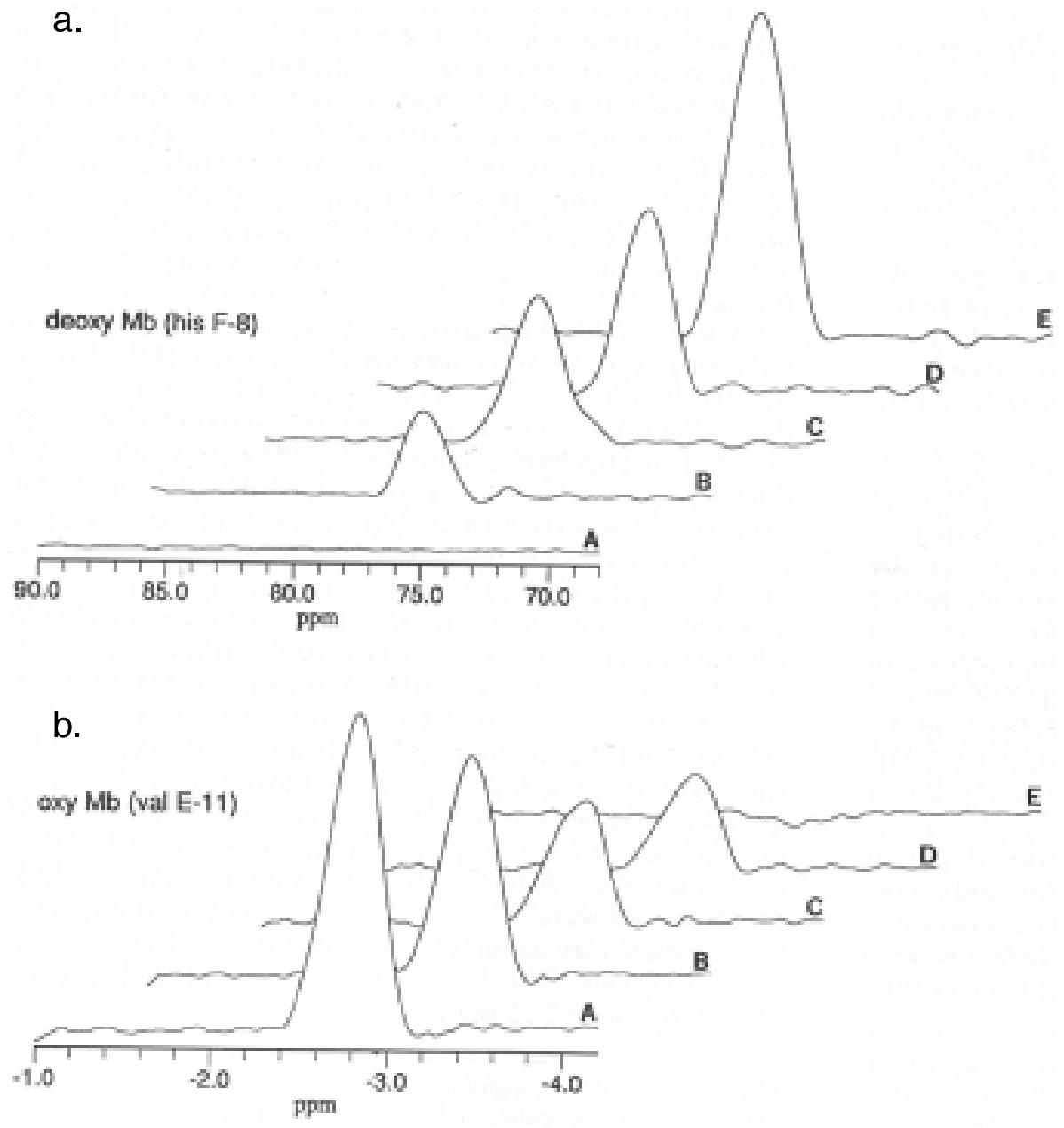

Fig. 13. ${ }^{1} \mathrm{H}$ NMR spectra of (a) deoxy-Mb from His-F8 $\mathrm{N} \delta$ proton at $-79.8 \mathrm{ppm}$ and (b) oxy-Mb from Val-E11 $\gamma$-methyl proton at $-2.76 \mathrm{ppm}$ in isclated perfused heart under various ischemic conditions. Hearts were initially perfused at a constant rate of $11 \mathrm{ml} / \mathrm{min}$ (trace A), the perfusion rate was then decreased stepwise to $3 \mathrm{ml} / \mathrm{min}$ (trace B), $2 \mathrm{ml} / \mathrm{min}$ (trace C), and $1 \mathrm{ml} / \mathrm{min}$ (trace D), and subsequently the perfusate flow was stopped completely (trace E) [90]. (with permission).

sity in the FNAB samples obtained in clinical settings, the signal-to-noise ratio of the metabolite signal often is insufficient for many samples to give conclusions. Mountford and co-workers demonstrated that this problem could be circumvented by a statistical classification strategy (SCS) that defined the spectroscopic pattern using all the NMR-detectable resonances from an FNAB sample [105]. The overall sensitivity and specificity were $93 \%$ and $92 \%$ of the 140 MRS spectra from the breast FNAB samples, as compared to those of $85 \%$ and $82 \%$, respectively, using visual inspection based on the ratio of choline signal and creatine signal. The SCS also predicts the lymph node involvement with an accuracy of $95 \%$ and the tumor vascular invasion with an overall accuracy of $94 \%$.
Breast tissue contains intense lipid and water signals that present a formidable technical obstacle to the efficient and reliable in vivo proton MRS detection of metabolites as surrogate markers of breast cancer. To date, choline is the only metabolite that has been observed reliably in human breast cancer by singlevoxel proton MRS (Fig. 14) [30,31,106-114], reaching a sensitivity and improved specificity of tumor detection of approximately $78 \%$ and $86 \%$, respectively. Jagannathan and colleagues showed that neoadjuvant chemotherapy caused either absence or reduction of total choline level in $89 \%$ of patients [111]. Garwood and co-workers observed a similar choline level drop after neoadjuvant chemotherapy for locally advanced breast cancer on a 4T MR scanner $[115,116]$. Choline also was used as a biomarker for axillary node metas- 

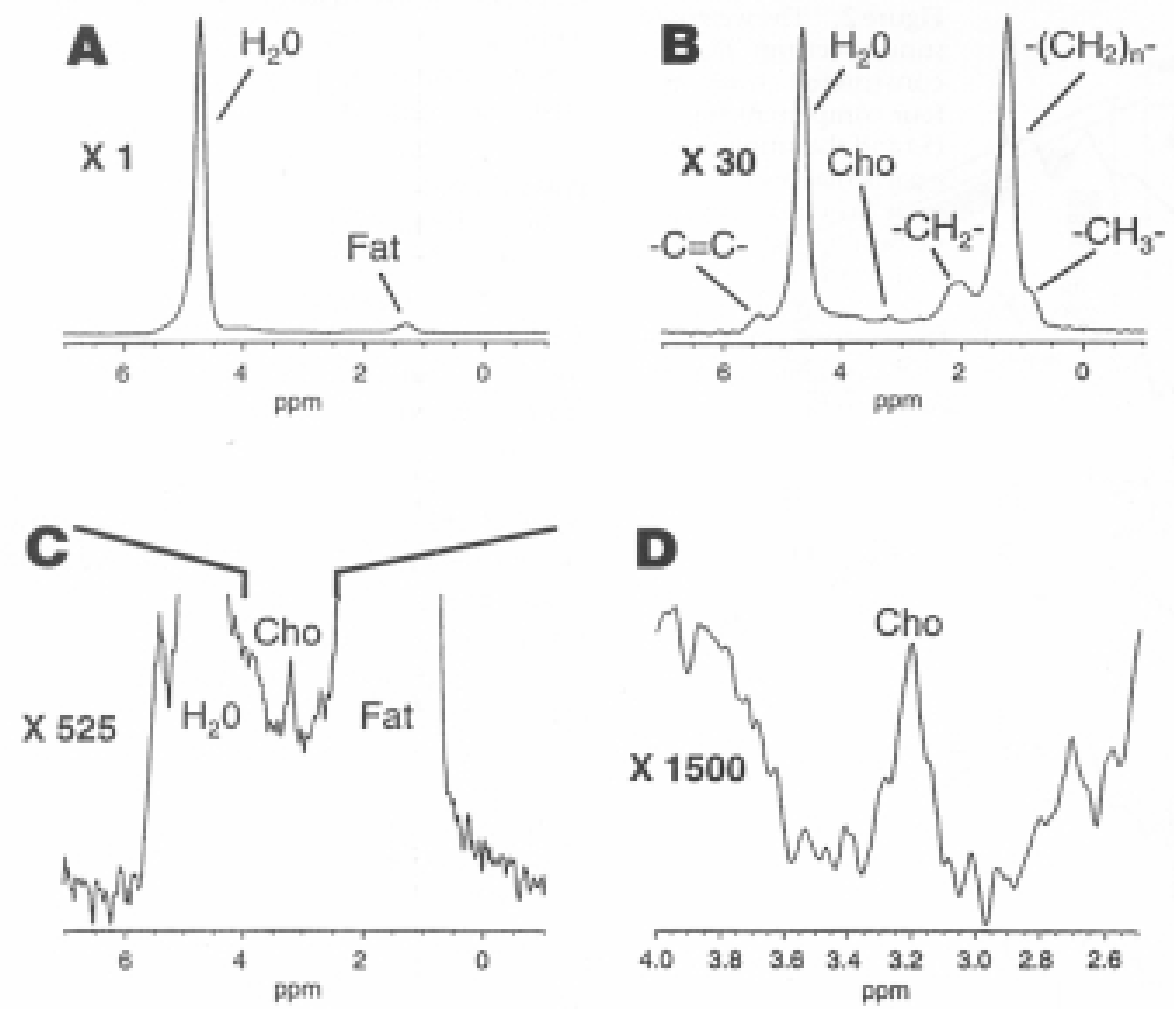

Fig. 14. Proton MRS spectra (B-D) of choline (Cho) from a single voxel localized around the lesion in the breast. Spectrum A shows a conventional MRS spectrum [110]. (with permission).

tasis of breast cancer with a sensitivity of $82 \%$, a specificity of $100 \%$, and an accuracy of $90 \%$, as compared with the ultrasonically guided FNAB findings in lymph nodes [114].

Of the various choline-containing compounds (choline, glycerophosphocholine, and phosphocholine) that contribute to the peak at $3.2 \mathrm{ppm}$ in ${ }^{1} \mathrm{H} \mathrm{MRS}$, an increase in phosphocholine is most probable [117]. This is consistent with the ${ }^{31} \mathrm{P}$ NMR observations that the metabolic changes in breast cancer lead to elevated PMEs composed of both phosphocholine (PC) and phosphatidylethnolamine (PE), which may be associated with rapid cell membrane biosynthesis. However, choline also was detected in lactating breast tissue that had a physiologically high metabolism without increase in cell proliferation [106,111]. Certain breast cancer types do not have elevated choline. Therefore, choline alone, detected in vivo by ${ }^{1} \mathrm{H}$ MRS, may not be a specific marker for breast tissue malignancy. The derivation of additional characteristic metabolic markers for breast cancer would be invaluable toward improving the diagnostic specificity of ${ }^{1} \mathrm{H}$ MRS in the evaluation of breast cancer.

\subsubsection{Feasibility of detecting lactate as a product of enhanced glycolysis in malignant breast tumors}

Over the past few years, we expended much effort to develop a family of proton MRSI methods, based on the Sel-MQC pulse sequence, that can achieve complete lipid and water suppression in a single scan to permit detection of low concentration metabolites, such as lactate, choline, and unsaturated lipid molecules, as surrogate biomarkers of breast cancer [32,33]. On a 2.1T Bruker Avance whole-body human MRI/MRS spectrometer, we successfully detected changing lactate levels in a milk phantom (12\% fat) in which lactate solutions were titrated. The measured signals were proportional to the amount of lactate present.

In an early patient study, a commercial body coil was used for RF transmission at $2.1 \mathrm{~T}$, and an $8 \mathrm{~cm}$ surface coil was used for signal receiving. A transverse gradient echo image was acquired to define the sagittal slice containing the tumor (Fig. 15a), in which the lactate and saturated lipid CSI maps subsequently were obtained using the Sel-MQC CSI sequence (Fig. 15b and 15c) [118]. The signal intensity from each pixel represents the integral of the lactate peak from the voxel 
$\left(0.14 \mathrm{~cm}^{3}\right)$. These results demonstrated the feasibility of mapping lactate and unsaturated lipid distributions in vivo in human breast cancer using proton MRSI. The poor signal-to-noise ratio reflects the small voxel size $\left(0.14 \mathrm{~cm}^{3}\right)$ chosen in this preliminary experiment. Note that the single voxel size for choline detection in breast cancer usually is $8 \mathrm{~cm}^{3}$ or larger. Sel-MQC will be more effective for lactate detection on higher field MRI/MRS scanners (3T or 7T). Work is in progress to evaluate the use of MRSI techniques to differentiate benign from malignant breast tumors.

\subsubsection{Unsaturated lipid as a biomarker of breast tissue changes and malignancy [119]}

Tumor cells express high levels of fatty acid synthesizing enzymes, use endogenously synthesized fatty acids for membrane biosynthesis, and export large amounts of lipids. Inhibition of fatty acid synthesis produces irreversible lethal injury, apoptotic DNA fragmentation, and morphological changes [120]. Fatty acid synthesis is, therefore, a potential target for antineoplastic therapy [121]. Fatty acid molecules can be tumor specific markers. Fatty acids detected by proton MRS have been used to distinguish benign lesions from invasive cancer ex vivo in various organs with biopsy specimens $[122,123]$. Non-invasive detection and monitoring of lipid metabolic changes in human breast cancer will provide valuable diagnostic markers and information on tumor lipogenetic biochemistry related to pathological conditions. Here we report preliminary results of human subject studies designed to map the spatial distributions of unsaturated lipids from the breast non-invasively to detect transformed breast tissue.

In the previous experiment involving Sel-MQC lactate detection in human breast cancer, we observed a residual multiple-quantum lipid signal at $2.8 \mathrm{ppm}$ from allylic methylene protons $\left(-\mathrm{CH}_{2}-\mathrm{CH}_{2}-\mathrm{CH}=\right)$ of the unsaturated acyl chain of lipids (Fig. 15c), which passed through the lactate MQ-filter because of its spin-spin coupling to the olefinic methylene protons $(-C \mathbf{H}=C \mathbf{H}-)$ of the unsaturated lipid at 5.3 ppm [118]. The increased unsaturated lipid level was observed in the ex vivo MRS experiments of human liposarcoma biopsy samples, which correlates with tumor mitotic activities [124]. We subsequently studied volunteer human subjects and breast cancer patients to obtain normal and pathological spatial distributions of unsaturated fatty acids. A single transmit/receive coil was used to detect unsaturated lipid resonance at 5.3 ppm on the 2.1T human MRI/MRS spectrometer. Con- tinuous distributions of unsaturated lipid signals were observed often in healthy breast tissue, and sometimes unsaturated lipids are more concentrated in breast tissue areas with high ductal gland density. In $\mathrm{T}_{1}$-weighted MRI experiments (without contrast-enhancement), discontinuous distributions of the unsaturated lipids were observed in women with hyperintensive breast areas in the $\mathrm{T}_{1}$-weighted images. In the hyperintensive breast areas, unsaturated lipid signals either disappeared or were reduced. A broken pattern of unsaturated lipid distributions also was observed in cancerous breast lesions (He et al., unpublished data). The MR-visible unsaturated lipids may serve as an index of premalignant breast lesions.

\subsection{Clinical MRSI of brain tumors}

\subsubsection{MRSI markers of neurological disorders and brain cancers}

In vivo MRS techniques for studying the human brain in normal and pathological conditions are well developed and require only suppressing the intense water signals and the pericranial fat from the scalp, skull, and calvarial marrow using standard spatial localization techniques. We will not exhaustively review the large body of literature on MRS of brain tumors, but will consider only a few examples of using metabolite markers for brain tumor diagnosis and prognosis. Readers should consult the many excellent reviews on brain MRSI applications. The most important brain metabolites are: $\mathrm{N}$-acetyl aspartate (NAA) at $2.0 \mathrm{ppm}$, which represents functional neurons; choline-containing compounds (Cho), including phosphocholine, glycerophosphocholine, and acetylcholine, which reflect cell membrane metabolism and cellularity; creatine (CR) at 3.0 and $3.94 \mathrm{ppm}$, which represents cellular energy status; myoinositol at $3.56 \mathrm{ppm}$; the glycolysis product lactate at $1.32 \mathrm{ppm}$; alanine at $1.5 \mathrm{ppm}$; and lipids at 0.8 and $1.3 \mathrm{ppm}$. Clinical brain MRSI scans usually are performed after contrast-enhanced fast MRI procedures (Fig. 16, upper left image) that provide high-resolution brain anatomical maps for superpositioning metabolite distributions from MRSI (the other three images in Fig. 16 for Cho, CR and NAA) to identify possible tumor regions. Tumors usually present increased choline levels, decreased levels of NAA, detectable lactate, and increased lipid concentrations.

MRSI improves the diagnostic specificity of tumors with elevated choline concentrations (Fig. 16, upper right) with decreased NAA concentration, which indicates a loss of neuronal activities in the tumor re- 


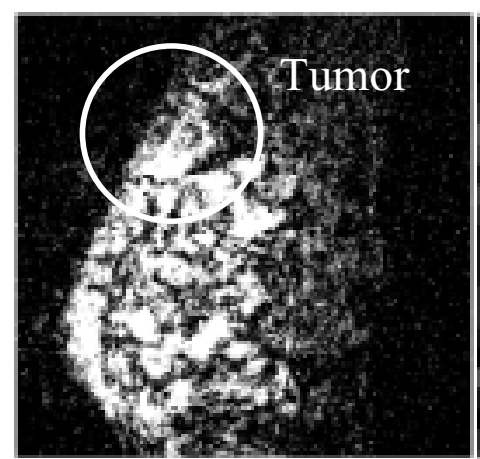

(a)

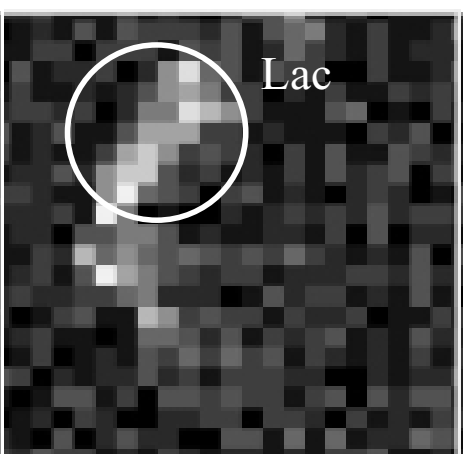

(b)

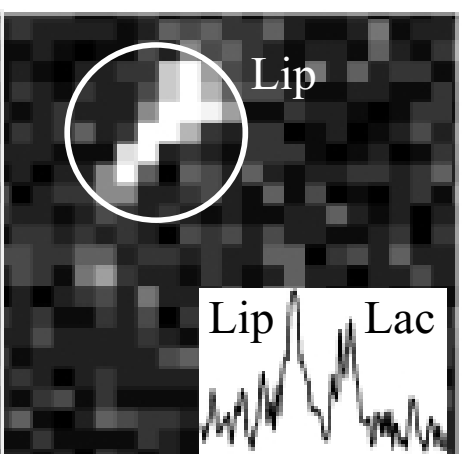

(c)

Fig. 15. (a) The gradient echo image $(256 \times 256)$ from a $1 \mathrm{~cm}$ sagittal slice containing a breast tumor. FOV $=12 \mathrm{~cm}$ and $\mathrm{TE}=10 \mathrm{~ms} .(\mathrm{b})$ Lactate CSI map (possibly contaminated by residual lipid) and (c) unsaturated lipid distribution $(32 \times 32)$ were obtained in 40 min from the same slice. The poor signal-to-noise ratio reflects the small voxel size chosen in this experiment $\left(0.14 \mathrm{~cm}^{3}\right)$ [118]. (Shkarin and He, unpublished data).

$\mathrm{C}+\mathrm{MRI}$

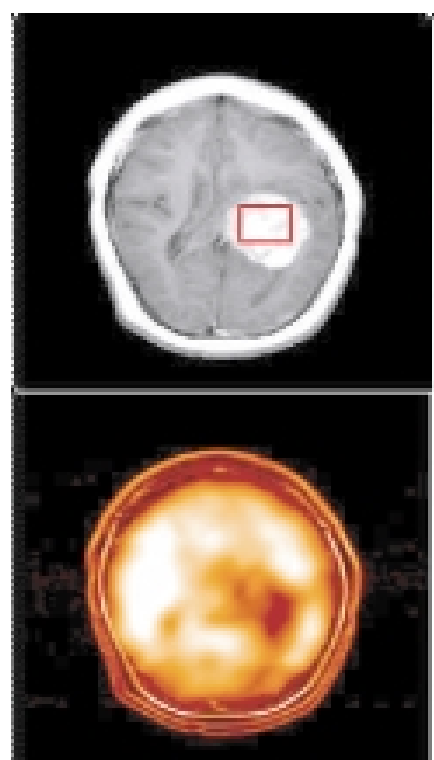

CR
$\mathrm{CHO}$

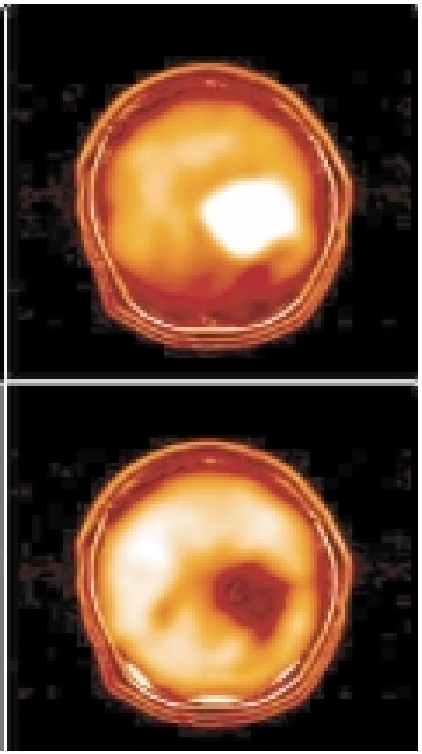

NAA

Fig. 16. Post-contrast MRI and brain metabolite spectroscopic images of a 14-year-old male subject with a histopathologically confirmed WHO grade III choroid plexus carcinoma. The spectroscopic imaging data were recorded using the multislice MRSI technique of Duyn et al. (1993), with TE/TR 280/2300 ms, four 15 -mm slices, $3.5 \mathrm{~mm}$ inter-slice gaps, $32 \times 32$ phase-encoding steps with circular k-space sampling, and 256 complex sample points zerofilled to 1024 prior to standard 3D fast Fourier transformation. The metabolite images are fused with the corresponding MR image. This tumor shows no NAA or creatine and an increased choline level. The absence of NAA in the tumor is consistent with its non-neuronal origin. (Shungu et al., unpublished data).

gion (Fig. 16, lower right). Often, increased lactate levels are observable in proliferating or high-grade tumors. Meningiomas are unique and have a distinct marker, alanine at $1.48 \mathrm{ppm}$. When choline is elevated by two standard deviations (SDs) above normal levels and when NAA decreases by two SDs below normal concentrations, biopsy specimens show active tumors in all cases. When choline levels are elevated less than two SDs from the normal but greater than the NAA level drop, histological analysis shows tumors in $85 \%$ of biopsy specimens [125]. Elevated lactate has been observed mostly in high-grade brain tumors [126-128] 
and in necrotic tumor regions [129]. However, not all high-grade brain tumors have detectable lactate. A recent study showed that higher lactate concentrations in tumors correlated with poor patient survival [130]. In a recent clinical investigation of 176 brain cancer patients, 97 cases were diagnosed correctly with conventional MRI alone $(55.1 \%)$. When the information from ${ }^{1} \mathrm{H}$-MRS was added, the correct diagnosis rate increased to $124(70.5 \%)$ [131]. In most studies using short echo times (e.g., TE $=18 \mathrm{~ms}$ ), lactate signal distribution was not reported because the elevated lipid resonances obscured the observation of lactate at $1.3 \mathrm{ppm}$. When lipid is produced in brain tumors, SelMQC would be ideal for lactate detection with complete lipid suppression. Interestingly, increased lipid might indicate high-grade tumors. Tumors with intermingled micronecrosis and cells of high neoplastic potential have shown low or no Cho signal but a high level of lipid (or lactate) [132].

Although the single voxel technique is easier, faster, and commercially available for clinical brain cancer diagnosis, the multi-voxel technique of CSI improves diagnosis of tumors because of the heterogeneity of tumor lesions. This was illustrated with the MRSI data from an HIV patient (Shungu et al., data not shown).

\subsubsection{Differentiation of high-grade tumors from metastasis}

Tumor cell infiltration outside MRI contrast-enhancing areas, which usually indicates malignancy, can be identified by biochemical changes in tumor cells detectable in vivo by MRS. This overcomes MRI difficulties in differentiating tumor recurrence and therapyrelated benign tissue changes. During a study reported recently, MRSI detection of Cho signals outside the Gd-DTPA-enhanced tumor bed gave the sites of tumor recurrence [132]. Tumor-cell infiltration into the peritumoral regions of high-grade gliomas generated detectable choline elevations (Fig. 17). In a study of 33 patients, including 18 patients with metastases, no abnormal metabolite signal was detected in the brain metastasis (choline/creatine ratio $=0.76 \pm$ 0.23 ), whereas elevated choline levels were observed in the peritumoral region of high-grade gliomas (2.28 \pm 1.24 ) [133]. In the small-sized metastases studied, lipid and lactate signals are not apparent $[134,135]$. In large metastatic tumors, lipid and lactate signals increase, which may be caused by tumor necrosis. Although more studies are necessary to establish clinical diagnostic criteria, MRSI has demonstrated the power to detect and differentiate tumors of different grades and metastases, and to identify recurrent tumors even when anatomic landmarks disappear after therapy.

\subsubsection{Diffusion MRS as a potential tool in cancer prognosis}

The emerging field of diffusion MRSI may play an important role in the therapeutic prognosis of human cancers [136]. The conventional detection of water diffusion coefficients cannot differentiate between intracellular compartments and extracellular space due to the fast exchange of water between the compartments. Diffusion MRSI experiments can be designed to measure intracellular metabolites such as choline and NAA with a diffusion displacement smaller than the cell diameter (e.g., $5 \mu \mathrm{m}$ ). Destroying tumor cells during therapeutic interventions releases metabolites into the extracellular space. The diffusion coefficients of intracellular metabolites increase after therapy with reduced cell matrix restrictions. Therefore, the effectiveness of cancer therapy potentially can be monitored by changes in the diffusion coefficients of intracellular tumor metabolites. In an animal study of apoptosis, choline diffusion decreased while cells went through programmed cell death, indicating that the cells are intact and retain cell integrity and selective permeability of the plasma membrane. This principle needs to be verified in clinical trials during therapeutic interventions of human cancers [137].

\subsection{Clinical MRSI of prostate cancer}

The extensive study of MRSI in prostate cancer represents another exciting clinical success, using combined MRSI/MRI for tumor detection and monitoring of therapeutic responses [138-140]. Serum prostatespecific antigen (PSA) screening and transrectal ultrasound (TRUS)-guided biopsies of lesions palpable on digital rectal examination (DRE) are the major methods for clinical diagnosis, staging, and treatment planning for prostate cancer. Because of the multifocal, multicentric nature of the disease, detection, localization, and accurate staging of individual tumor foci in the prostate have been challenging. TRUS-guided biopsies fail to detect 8-30\% of DRE-palpable lesions, and 30$60 \%$ of tumors are understaged. $\mathrm{T}_{2}$-weighted MRI has markedly improved accuracy in detecting extracapsular extension (81\%) and seminal vesicle invasion (96\%) of the disease and has improved staging accuracy to 75$90 \%$. The specificity of MRI remains fairly low (27\%), even with high sensitivity $(91 \%)$ for prostate cancer detection [138,141]. The large number of false positives are related to post-biopsy hemorrhage, prostatitis, and therapeutic-related blurring of prostate anatomical margins. A high specificity, up to $91 \%$, was achieved 

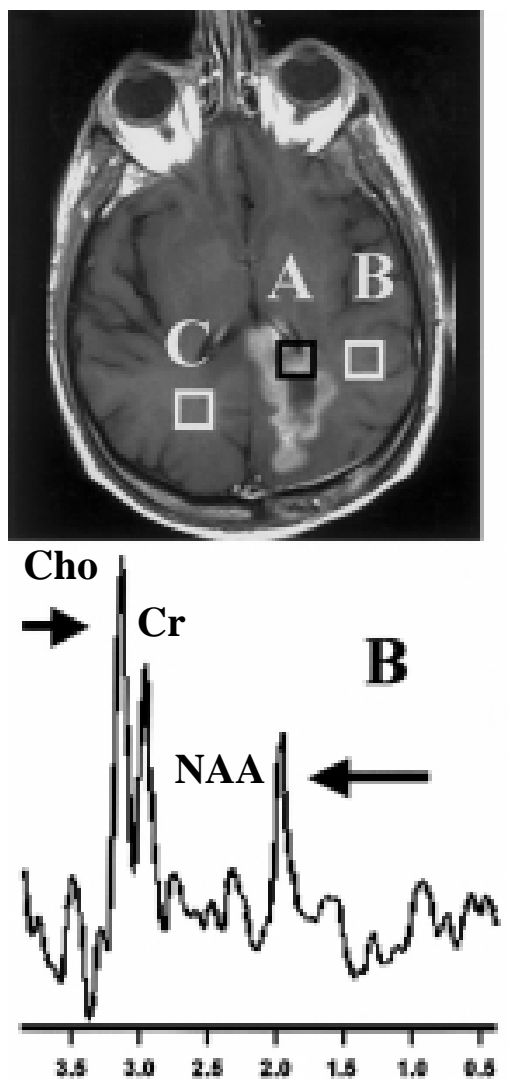
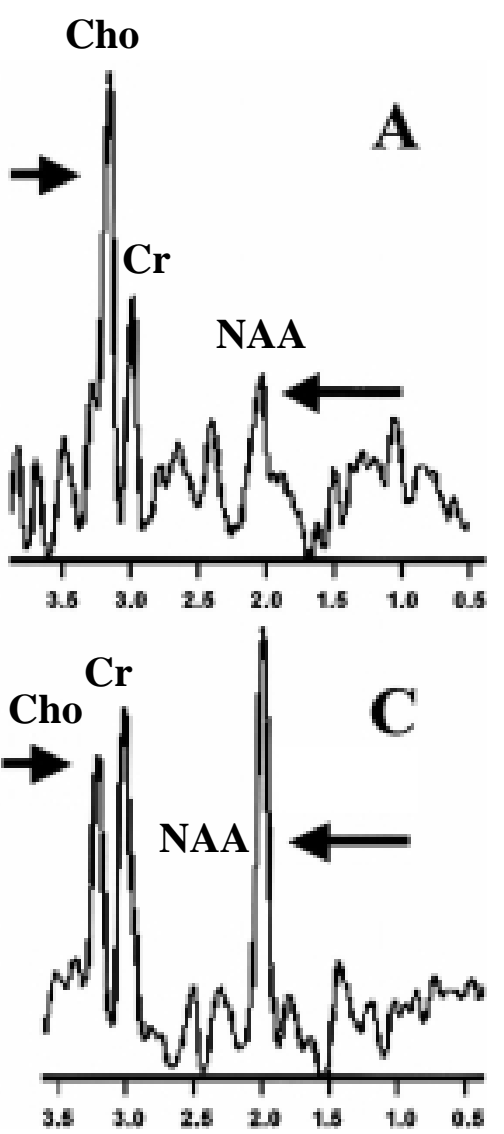

Fig. 17. Localized image from post-contrast transverse $\mathrm{T}_{1}$-weighted $\mathrm{MR}$. (A): intramural spectrum; (B): peritumoral region with elevated $\mathrm{Cho} / \mathrm{Cr}$ and reduced NAA/Cr, indicating the tumor infiltration of a histopathologic glioblastoma multiforme; (C): the control spectrum from the contralateral normal brain tissue [133]. (with permission).

by combining 3D MRSI and $\mathrm{T}_{2}$-weighted MRI, and high MRI sensitivity (95\%) was maintained [142].

When the cancer is detectable by both MRI and MRSI, the MRSI detection of prostate cancer in a sextant in the peripheral zone (Fig. 18), based on the ratio of [choline + creatine] and citrate, gives a positive predictive value of $89-92 \%$ ( $>2$ SDs possible cancer and $>3$ SDs definite cancer). When cancer is absent in both MRI and MRSI, the negative predictive value for excluding cancer is $74-82 \%$ [142]. Normal prostate epithelial cells secrete citrate that accumulates in the extracellular space in prostate tissue more than in other soft tissues as a result of high zinc levels that inhibit acinitase and prevent citrate oxidation in the TCA cycle. In prostate cancer, the characteristic ductal morphology of prostate tissue is lost, and zinc concentration decreases due to disrupted zinc transport. Prostate cancer cells lose the ability to secrete and accumulate citrate, accelerating citrate turnover rates. Citrate levels are grade-dependent in prostatic adenocarcinomas and low in high-grade prostate cancer. The mechanisms for choline elevation are related to an increased rate of cell proliferation and high cell density in the tumor region and to changes in the membrane composition of phospholipids. The $3.2 \mathrm{ppm}$ signal originates not only from total choline (contributions of choline), phosphocholine, glycerophosphocholine), but also from polyamines, ethanolamine, phosphoethanolamine, inositol, and taurine. Creatine concentration presents no distinctive difference between prostate cancer and normal prostate tissues.

Kurhanwicz and co-workers showed that MRSI was useful in monitoring the response of therapy, especially when anatomical landmarks were destroyed by radiation or chemotherapy [138]. For example, branchytherapy treatment usually erases the anatomical features in the prostate, which produces a featureless, homogeneous $\mathrm{T}_{2}$-weighted image of the prostate gland. By giving a definitive diagnosis of cancer location and healthy 


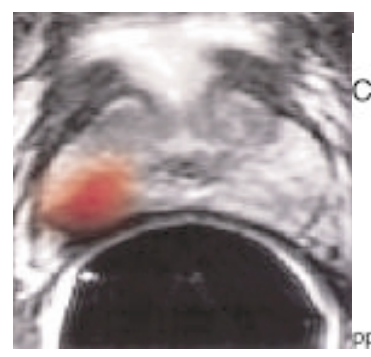

(a)

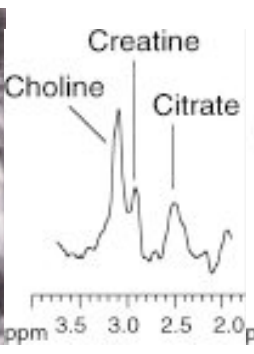

(b)

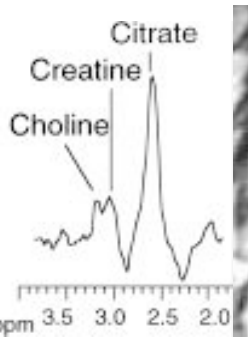

(c)

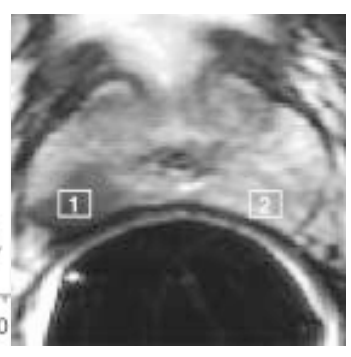

(d)

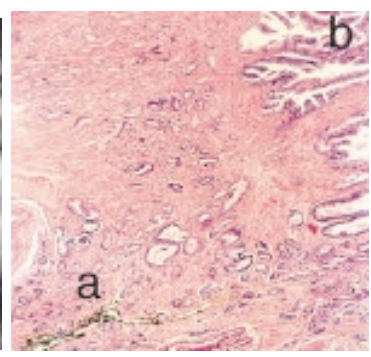

(e)

Fig. 18. Histopathologic stage pT3a prostate cancer, Gleason score 5, in a 58-year-old man. (a) Fast spin-echo $\mathrm{T}_{2}$-weighted (5,000/102) transverse MR image through the middle of the gland was obtained with an endorectal coil. A tumor focus is seen as an area of decreased signal intensity in the peripheral zone of the right gland (on the left of the image), as demonstrated with 3D MRSI findings overlaid in red. (b) MR spectrum obtained from area of imaging abnormality ( 1 in d) of definite cancer with elevated choline and reduced citrate. (c) A control spectrum obtained from a normal left peripheral zone ( 2 in d) represents the normal spectral pattern with citrate dominant and no abnormal elevation in choline. (d) The fast spin-echo MR transverse image depicts an area of imaging abnormality in the right peripheral zone (1) and a normal left peripheral zone (2) [142]. (with permission).

prostate tissues, MRSI can assist branchytherapy and other therapy planning.

Currently, clinical MRSI diagnosis of prostate cancer is limited mainly to the peripheral zone of the prostate gland. The transition zone displays reduced citrate levels due to a reduced glandular cell density. MRSI-detectable choline elevation is the only possible metabolic indication of tumor tissue. Combined choline and MRI markers are being investigated actively for prostate cancer detection in the transition zone [143]. In principle, lactate and unsaturated lipids are two additional potential markers for tumor detection in both the transition and peripheral zones of the prostate gland using Sel-MQC. As MRSI research in this direction unfolds, the specificity of prostate cancer diagnosis will improve further.

\section{Future perspectives-Ultra-fast 3D MRSI of cancer}

Compared with the highly sensitive optical and X-ray imaging modalities of cancer diagnosis, MR has less intrinsic sensitivity; however, it provides superb tissue penetration depth without using ionizing radiation. MRI offers excellent imaging contrast for identifying soft tissue tumors that can be enhanced by injection of paramagnetic contrast agents. MRS provides biochemical information specific to tumor malignancies. The major limitation of MRSI is its low temporal and spatial resolution. MR is in the low energy range of the electromagnetic spectrum. The small population difference of nuclear spins in the ground and excited en- ergy states at the physiological temperature, determines its low intrinsic sensitivity of MRS. The limitations of MRS also derive from the low tissue concentrations of metabolites, drugs, $\mathrm{pH}$ indicators, and proteins, as well as the severe signal overlaps between these molecules. We showed strategies of spectroscopic editing to selectively detect molecules of interest in tissues containing high concentrations of fat. Isotopic and chemical labeling of compounds have been used to determine the metabolic flux in vivo without background signals from other molecules. In MR molecular imaging experiments, contrast-agent-conjugated antibodies or ligands are used to selectively label proteins for observation [144-147]. Signal sensitivity enhancement may be possible via intermolecular coherence transfer for molecules of low tissue concentration [148-150]. Fast imaging schemes can be employed to improve MRSI sensitivity. For example, echo-planar MRSI methods using fast k-space mapping reduce scanning time without sacrificing signal-to-noise ratios [151-154]. The SENSE [155] technique of parallel imaging has been used to improve the spatial resolution of MRSI, taking advantage of multi-coil configurations on the clinical scanners to reduce the field of view (FOV) and scanning time. Most of the fast MRSI sequences are incapable of suppressing endogenous mobile lipid signals. We are developing ultra-fast 3D Sel-MQC sequences to investigate breast cancer and malignant diseases in other extracranial organs. The characteristics of tumor malignancy can be extracted using numerical signal processing approaches, combining the tissue information obtained from 3D MRSI, 3D dynamic MRI, and other 3D imaging modalities. The capability to gener- 
ate high-quality digital images is essential, not only for cancer diagnosis and detection, but also for future clinical cancer interventions using robot-assisted surgical procedures [156-158].

\section{Acknowledgements}

We thank Drs. Michael Garwood for providing the 4T MRS data from human breast cancer, Jerry D. Glickson and Zaver M. Bhujwalla for helpful discussions, and Alan A. Alfieri for reading the manuscript. The work was supported by grants from the Susan G. Komen Breast Cancer Foundation (Grant\# 9601 and IMG0100117), the National Institutes of Health (NIH R21CA80906), Translational Medicine Funds from the Memorial Sloan-Kettering Cancer Center (to QH), and by the Distinguished Cancer Scientist Development Fund of Georgia Cancer Coalition (to HS).

\section{References}

[1] R. Ernst, R. Bodenhausen and G. Wokaun, A. Principle of nuclear magnetic resonance in one and two dimensions; Oxford Science Publications: Oxford, 1987, pp. 482-485.

[2] J. Casciari, J. Sotirchos and S.V. Sutherland, R.M. Mathematical modelling of microenvironment and growth in EMT6/Ro multicellular tumour spheroids, Cell Prolif 25 (1992), 1-22.

[3] R.M. Sutherland, B. Sordat, J. Bamat, H. Gabbert, B. Bourrat and W. Mueller-Klieser, Oxygenation and differentiation in multicellular spheroids of human colon carcinoma, Cancer Research 46 (1986), 5320-5329.

[4] R.E. Wilson, P.C. Keng and R.M. Sutherland, Changes in growth characteristics and macromolecular synthesis on recovery from severe hypoxia, Br. J. Cancer 61 (1989), 14-21.

[5] R.M. Sutherland, Cell and environment interactions in tumor microregions: the multicelll spheroid model, Science $\mathbf{2 4 0}$ (1988), 177-184.

[6] A.J. Giaccia, Hypoxic stress proteins: Survival of the fittest, Semin. Radiat. Oncol. 6 (1996), 46-58.

[7] O. Warburg, The metabolism of tumours; Constable\&Co, Ltd: London, 1930.

[8] P.L. Pedersen, Tumor Mitochondria and the Bioenergetics of Cancer Cells, Prog. Exp. Tumor Res. 22 (1978), 190-274.

[9] D.J. Templeton and R.A. Weinberg, in: American cancer society textbook of clinical oncology, A.I. Holleb, D.J. Fink and G.P. Murphy, ed., American cancer society: Atlanta, 1991, pp. 678-690.

[10] K.A. Brand and U. Hermfisse, Aerobic glycolysis by proliferating cells: a protective strategy against reactive oxygen species, FASEB J 11 (1997), 388-395.

[11] G. Semenza, D. Artemov, A. Bedi, Z. Bhujwalla, K. Chiles, D. Feldser, E. Laughner, R. Ravi, J. Simons, P. Taghavi, $\mathrm{H}$. Zhong, in: The tumour microenvironment: causes and consequences of hypoxia and acidity, J.A. Goode and D.J. Chadwick, ed., John Wiley \& Sons: New York, 2001.
[12] K.C. Chung, D. Huang, Y. Chen, S. Short, M.L. Short, Z. Zhang and R.A. Jungmann, Identification of a silencer module which selectively represses cyclic AMP-responsive element-dependent gene expression, Mol Cell Biol 15 (1995), 6139-6149.

[13] D. Huang and R.A. Jungmann, Transcriptional regulation of the lactate dehydrogenase A subunit gene by the phorbol ester 12-O-tetradecanoylphorbol-13-acetate, Mol Cell Endocrinol 108 (1995), 87-94.

[14] L.M. Matrisian, G. Rautmann, B.E. Magun and R. Breathnach, Epidermal growth factor or serum stimulation of rat fibroblasts induces an elevation in mRNA levels for lactate dehydrogenase and other glycolytic enzymes, Nucleic Acids Res 13 (1985), 711-726.

[15] M.L. Short, D. Huang, D.M. Milkowski, S. Short, K. Kunstman, C.J. Soong, K.C. Chung and R.A. Jungmann, Analysis of the rat lactate dehydrogenase A subunit gene promoter/regulatory region, Biochem J 304 (1994), 391-398.

[16] W. Negendank, Studies of Human Tumors by MRS: a Review, NMR in Biomedicine 5 (1992), 303-324.

[17] J.M. Maris, B.S. Audrey, E. Evans, A.C. McLaughlin, G.J. D'Angio, L. Bolinger, H. Manos and B. Chance, ${ }^{31} \mathrm{P}$ Nuclear magnetic resonance spectroscopic investigation of human neuroblastoma in situ, The New England Journal of Medicine 312 (1985), 1500-1505.

[18] H.D. Sostman, D.M. Prescott, M.W. Dewhirst, R.K. Dodge, D.E. Thrall, R.L. Page, J.A. Tucker, J.M. Harrelson, G. Reece and K.A. Leopold, MR imaging and spectroscopy for prognostic evaluation in soft-tissue sarcomas, Radiology $\mathbf{9 0}$ (1994), 269-275.

[19] M.O. Leach, M. Verrill, J. Glaholm, T.A.D. Smith, D.J. Collins, G.S. Payne, J.C. Sharp, S.M. Ronen, V.R. McCready, T.J. Powles and I.E. Smith, Measurements of human breast cancer using magnetic resonance spectroscopy: A review of clinical measurements and a report of localized ${ }^{31} \mathrm{P}$ measurements of response to treatment, NMR Biomed 11 (1998), 314-340.

[20] A. Haase, J. Frahm, W. Haenicke and D. Matthei, ${ }^{1}$ H NMR chemical shift selective (CHESS) imaging, Phys. Med. Biol. 30 (1985), 341.

[21] T. Brown, B. Kincaid and K. Ugurbil, NMR chemical shift imaging in three dimensions, Proc. Natl. Acad. Sci. (1982), 3523-3526.

[22] P.A. Bottomley, Selective volume method for performing localized NMR spectroscopy, US Patent 4 (1984), 480228.

[23] J. Frahm, K.-D. Merboldt and W. Hanicke, Localized proton spectroscopy using stimulated echoes, J. Magn. Reson. 72 (1987), 502-508.

[24] R.A. De Graaf, In vivo NMR spectroscopy: principles and techniques, John Wiley \& Sons: New York, 1998, 508.

[25] S. Singh and B.K. Rutt, Projection Presaturation: A fast and accurate technique for multidimensional spatial localization, J. Magn. Reson. 87 (1990), 567-583.

[26] S. Singh, B.K. Rutt and S. Napel, Projection presaturation. II. Single-shot Localization of multiple regions of interest, $J$. Magn. Reson. 90 (1990), 313-329.

[27] D.C. Shungu and J.D. Glickson, Sensitivity and localization enhancement in multinuclear in vivo NMR spectroscopy by outer volume presaturation, Magn. Reson. Med. 30 (1993), 661-671.

[28] E.L. Hahn, Spin echoes, Phys. Rev. 80 (1950), 580-594.

[29] P.E. Sijens, H.K. Wijrdeman, M.A. Moerland, C.J.G. Bakker, J.W.A.H. Vermeulen and P.R. Luyten, Human breast cancer 
in vivo: $\mathrm{H}-1$ and $\mathrm{P}-31 \mathrm{MR}$ spectroscopy at $1.5 \mathrm{~T}$, Radiology 169 (1988), 615-620.

[30] J.R. Roebuck, R.E. Lenkinski and M.D. Schnall, Spatially localized proton magnetic resonance spectroscopy of human breast disease at 1.5T, Proc. Intl. Soc. Mag. Reson. Med. 2 (1996), 1247.

[31] J.R. Roebuck, R.E. Lenkinski, L. Bolinger and M.D. Schnall, Proton magnetic resonance spectroscopy of human breast at 4.0 T, Proc. Intl. Soc. Mag. Reson. Med. 2 (1996), 1246.

[32] Q. He, D.C. Shungu, P.C.M. van Zijl, Z.M. Bhujwalla and J.D. Glickson, Single scan in vivo lactate editing with complete lipid and water suppression by selective multiple quantum coherance transfer (Sel-MQC) with application to tumors, J. Magn. Reson. B 106 (1995), 203-211.

[33] Q. He, Z.M. Bhujwalla and J.D. Glickson, Proton detection of choline and lactate in EMT6 tumors by spin-echo-enhanced selective multiple-Quantum Coherence Transfer, J. magn. Reson., Series B 112 (1996), 18-25.

[34] Q. He, Z.M. Bhujwalla, R.J. Maxwell, J.D. Griffiths and J.D. Glickson, Proton observation of the antineoplastic agent Iproplatin in vivo by selective multiple quantum coherence transfer (Sel-MQC), Magn. Reson. Med. 33 (1995), 414-416.

[35] Z.M. Bhujwalla, D.C. Shungu, Q. He, J.P. Wehrle and J.D. Glickson, MR studies of tumors: Relationship between blood flow, metabolism and physiology, in: NMR in Physiology and Biomedicine, R.J. Gillies, ed., Academic Press: San Diego, 1994, pp. 311-328.

[36] R.A. De Graaf, R.M. Dijkhuizen, G.J. Biessels, K.P. Braun and K. Nicolay, In vivo glucose detection by homonuclear spectral editing, Magn. Reson. Med. 43 (2000), 621-626.

[37] D.C. Shungu, A.G. Palmer, III, R. Ramasamy and X. Mao, Simultaneous detection of GABA and glutamate by selective multiple-quantum coherence transfer, Proc. Intl. Soc. Mag. Reson. Med. 11 (2003), 1140.

[38] D.M. Freeman, C.H. Sotak, H.H. Muller, S.W. Young and R.E. Hurd, A double quantum coherence transfer proton NMR spectroscopy technique for monitoring steady-state tumor lactic acid levels in vivo, Magn. Reson. Med. 14 (1990), 321-329.

[39] D.C. Shungu, Z.M. Bhujwalla, J.P. Wehrle and J.D. Glickson, ${ }^{1} \mathrm{H}$ NMR spectroscopy of subcutaneous tumors in mice: preliminary studies of effects of growth, chemotherapy and blood flow reduction, NMR Biomed 5 (1992), 296-302.

[40] Z.M. Bhujwalla and J.D. Glickson, Detection of tumor response to radiation therapy by in vivo proton MR spectroscopy, Int. J. Radiat. Oncol. Biol. Phys. 36 (1996), 365369.

[41] E.O. Aboagye, Z.M. Bhujwalla, Q. He and J.D. Glickson, Evaluation of lactate as a ${ }^{1} \mathrm{H}$ nuclear magnetic resonance spectroscopy index for noninvasive prediction and early detection of tumor response to radiation therapy in EMT6 tumors, Radiat. Res. 150 (1998), 38-42.

[42] H. Poptani, N. Bansal, R.A. Graham, A. Mancuso, D.S. Nelson and J.D. Glickson, Detecting early response to cyclophosphamide treatment of RIF-1 tumors using selective multiple quantum spectroscopy (SelMQC) and dynamic contrast enhanced imaging, NMR Biomed 16 (2003), 102-111.

[43] J.E. Biaglow, Y. Manevich, D.B. Leeper, B. Chance, M.W. Dewhirst, W.T. Jenkins, S.W. Tuttle, K. Wroblewski, J.D. Glickson, C. Stenvens and S.M. Evans, MIBG inhibits respiration: potential for radio- and hyperthermic sensitization, Int. J. Radiat. Oncol. Biol. Phys. 42 (1998), 871-876.

[44] R. Zhou, N. Bansal, D.B. Leeper, S. Pickup and J.D. Glickson, Enhancement of hyperglycemia-induced acidification of human melanoma xenografts with inhibitors of respiration and ion transport, Acad. Radiol. 8 (2001), 571-582.

[45] R. Zhou, N. Bansal, D.B. Leeper and J.D. Glickson, Intracellular acidification of human melanoma xenografts by the respiratory inhibitor m-Iodobenzylguanidine plus hyperglycemia: A ${ }^{31} \mathrm{P}$ magnetic resonance spectroscopy study, Cancer Res 60 (2000), 3532-3536.

[46] D.R. Newell, R.J. Maxwell and B.T. Golding, In vivo and ex vivo magnetic resonance spectroscopy as applied to pharmacokinetic studies with anticancer agents: a review, $N M R$ Biomed 5 (1992), 273-278.

[47] G.N. Hortobagyi, D. Frye, F.A. Holmes, V. Hug, G. Fraschini and A.U. Buzdar, Phase II study of Iproplatin in metastatic breast carcinoma, Cancer Treat. Rep. 71 (1987), 1193-1196.

[48] H.C. Nauts, W.E. Swift and B.L. Coley, The treatment of malignant tumors by bacterial toxins as developed by the late William B. Coley, M. D., Reviewed in the Light of Modern Research, Cancer Research 6 (1946), 205-216.

[49] J.M. Pawelek, B.K. Low and D. Bermudes, Tumor-targeted Salmonella as a novel anticancer vector, Cancer Research 57 (1997), 4537-4544.

[50] B.K. Low, M. Ittensohn, T. Le, J. Platt, S. Sodi, M. Amoss, O. Ash, E. Carmichael, A. Chakraborty, J. Fischer, S.L. Lin, X. Luo, S.I. Miller, L.-m. Zheng, I. King, J.M. Pawelek and D. Bermudes, Lipid A mutant Salmonella with suppressed virulence and $\mathrm{TNF} \alpha$ induction retain turmor-targeting in vivo, Nature Biotechnology 17 (1999), 37-41.

[51] K.C. Lee, L.-M. Zheng, X. Luo, C. Clairmont, J. Fischer, D. Margitich, J. Turnier, B. Almassian, D. Bermudes and I. King, Comparative evaluation of the acute toxic effects in monkeys, pigs and mice of a genetically engineered Salmonella strain (VNP20009) being developed as an antitumor agent, International Journal of Toxicology 19 (2000), 19-25.

[52] T. Dresselaers, P. Van Hecke, J. Theys, H. Callewaert, P. Lambin, J. Anne and W. Landuyt, Non-invasive ${ }^{19}$ F MR spectroscopy evaluation of Salmonella-based suicide gene transfer in rodent tumor models, Proc. Intl. Soc. Mag. Reson. Med. 11 (2003), 1284

[53] R.Z. Xu, J.J. Leffert, S. Sodi, I. King, J.M. Pawelek, E. Adams, Q. He and G. Pizzorno, Magnetic resonance spectroscopy (MRS) detection of lactic acid for Salmonella localization in tumors, Proc. Intl. Soc. Mag. Reson. Med. 10 (2002), 2168.

[54] O. Warburg, On the Origin of Cancer Cells, Science 123 (1956), 309-314.

[55] J. Tjuvajev, R. Blasberg, X. Luo, L.M. Zheng, I. King and D. Bermudes, Salmonella-based tumor-targeted cancer therapy: Tumor amplified protein expression therapy (TAPET) for diagnostic imaging, J. Controlled Release (2001).

[56] L.H. Dang, C. Bettegowda, D.L. Huso, K.W. Kinzler and B. Vogelstein, Combination bacteriolytic therapy for the treatment of experimental tumors, Proc. Natl. Acad. Sci. 98 (2001), 15155-15160.

[57] M.J. Brown and A.J. Giaccia, The unique physiology of solid tumors: opportunities (and problems) for cancer therapy, Cancer Research 58 (1998), 1408-1416.

[58] J.M. Star-Lack and D.M. Spielman, Zero-quantum filter offering single-shot lipid suppression and simultaneous detection of lactate, choline, and creatine resonances, Magn. Reson. Med. 46 (2001), 1233-1237.

[59] P. Barker, B.J. Soher, S.J. Blackband, J.C. Chatham, V.P. Mathews and R.N. Bryan, Quantitation of proton NMR spec- 
tra of the human brain using tissue water as an internal concentration reference, NMR in Biomedicine 6 (1993), 89-94.

[60] R. Kreis, T. Ernst and B.D. Ross, Absolute quantitation of water and metabolites in the human brain. II. Metabolite concentrations, J. Magn. Reson. Series B 102 (1993), 9-19.

[61] J.W. Pan, D.B. Twieg and H.P. Hetherington, Quantitative spectroscopic imaging of the human brain, Magn. Reson. Med. 40 (1998), 363-369.

[62] C.W. Li, W.G. Negendank, J. Murphy-Boesch, K. ParavicShaller and T.R. Brown, Molar quantitation of hepatic metabolites in vivo in proton-decoupled, nuclear overhauser effect enhanced ${ }^{31} \mathrm{P}$ NMR spectra localized by threedimensional chemical shift imaging, NMR Biomed 9 (1996), 141-155.

[63] M. Muruganandham, J.A. Koutcher and Q. He, T2 Relaxation measurements of lactate in abundant lipid environment by selective multiple quantum coherence transfer (SelMQC), Proc. Intl. Soc. Mag. Reson. Med. 10 (2002), 2284.

[64] E.O. Aboagye, N. Mori and Z.M. Bhujwalla, Effect of malignant transformation on lactate levels of human mammary epithelial cells, Advan. Enzyme Regul. 41 (2001), 251-260.

[65] H. Degani, S.M. Ronen and E. Furman-Haran, Breast Cancer: Spectroscopy and Imaging of Cells and Tumors, in: NMR in Physiology and Biomedicine, R.J. Gillies, ed., Academic Press: New York, 1994, pp. 329-351.

[66] J.G. Salway, Metabolism at a glance; Blackwell Science Ltd.: Oxford, 1995.

[67] C.F. Cori and C.T. Cori, The carbohydrate metabolism of tumors. II. Changes in the sugar, lactate acid, and $\mathrm{CO}_{2}-$ combining powers of blood passing through a tumor, J. Biol. Chem. 65 (1925), 397-405.

[68] O. Warburg, F. Wind and E. Negelein, Uber den stoffwechsel von tumoren im korper, Klin. Wschr. 5 (1926), 829-832.

[69] M. Terpstra, R. Gruetter, W.B. High, M. Mescher, L. Delabarre, H. Markle and M. Garwood, Lactate turnover in rat glioma measured by in vivo nuclear magnetic resonance spectroscopy, Cancer Research 58 (1998), 5083-5088.

[70] M. Mescher, A. Tannus, M.O.N. Johnson and M. Garwood, Solvent suppression using selective echo dephasing, J. Magn. Reson. Series A 123 (1996), 226-229.

[71] R.A. De Graaf, Y. Luo, M. Terpstra and M. Garwood, Spectral editing with adiabetic pulses, J. Magn. Reson. Series B 109 (1995), 184-193.

[72] D. Artemov, Z.M. Bhujwalla, U. Pilatus and J.D. Glickson, Two-compartment model for determination of glycolytic rates of solid tumors by in vivo ${ }^{13} \mathrm{C}$ NMR spectroscopy, NMR Biomed 11 (1998), 395-404.

[73] F.U. Nielsen, P. Daugaard, L. Bentzen, H. StodkildeJorgensen, J. Overgaard, M.R. Horsman and R.J. Maxwell, Effect of changing tumor oxygenation on glycolytic metabolism in a murine $\mathrm{C} 3 \mathrm{H}$ mammary carcinoma assessed by in vivo nuclear magnetic resonance spectroscopy, Cancer Research 61 (2001), 5318-5325.

[74] E.M. Chance, S.H. Seeholzer, K. Kobayashi and J.R. Williamson, Mathematical analysis of isotope labeling in the critric acid cycle with applications to ${ }^{13} \mathrm{C}$ NMR studies in perfused rat hearts, J. Bio. Chem. 258 (1983), 13785-13794.

[75] J.C. Chatham, J.R. Forder, J.D. Glickson and E.M. Chance, Calculation of absolute metabolic flux and the elucidation of the pathways of glutamate labeling in perfused rat heart by ${ }^{13} \mathrm{C}$ NMR spectroscopy and nonlinear least squares analysis, J. Bio. Chem. 270 (1995), 7999-8008.

[76] J.R. Williamson, S.H. Seeholzer and E.M. Chance, Flux analysis of ${ }^{13} \mathrm{CNMR}$ metabolite enrichments in perfused rat hearts using FACSIMILE, in: Simulation and Imaging of the Cardiac System, S. Sideman and R. Beyar, ed., Martinus Nijhoff Publishers: Boston, 1984, pp. 433.

[77] O.A.C. Petroff, G.D. Graham, A.M. Blamire, M. Al-Rayess, D.L. Rothman, P.B. Fayad, L.M. Brass, R.G. Shulman and J.W. Prichard, Spectroscopic imaging of stroke in humans: histopathology correlates of spectral changes, Neurology 42 (1992), 1349-1354.

[78] F. Hyder, R.G. Shulman and D.L. Rothman, A model for the regulation of cerebral oxygen delivery, J. Appl. Physiol. 85 (1998), 554-564.

[79] F. Hyder, R.P. Kennan, I. Kida, G.F. Mason, K.L. Behar and D.L. Rothman, Dependence of oxygen delivery on blood flow in rat brain: a 7 Tesla nuclear magnetic resonance study, $J$. Cerebral Blood Flow \& Metabolism 20 (2000), 485-498.

[80] T.L. Collier, R. Lecomte, T.J. McCarthy, S. Meikle, T.J. Ruth, F. Scopinaro, A. Signore, H. VanBrocklin, C. Van de Wiele and R.N. Waterhouse, Assessment of cancerassociated biomarkers by positron emission tomography: Advances and challenges, Disease Markers 18 (2002), 211247.

[81] R.J. Gillies, Z.M. Bhujwalla, J. Evelhoch, M. Garwood, M. Neeman, S.P. Robinson, C.H. Sotak and B. Van Der Sanden, Applications of magnetic resonance in model systems: Tumor biology and physiology, Neoplasia 2 (2000), 139-151.

[82] R. van Sluis, Z.M. Bhujwalla, N. Raghunand, P. Ballesteros, J. Alvarez, S. Cerdan, J.-P. Galons and R.J. Gillies, In vivo imaging of extracellular $\mathrm{pH}$ using ${ }^{1} \mathrm{H}$ MRSI, Magn. Reson. Med. 41 (1999), 743-750.

[83] Z.M. Bhujwalla, D. Artemov, P. Ballesteros, S. Cerdan, R.J. Gillies and M. Solaiyappan, Combined vascular and extracellular pH imaging of solid tumors, NMR Biomed 15 (2002), 114-119.

[84] Z.M. Bhujwalla, E.O. Aboagye, R.J. Gillies, V.P. Chacko, C.E. Mendola and J.M. Backer, Nm23-transfected MDAMB-435 human breast carcinoma cells form tumors with altered phospholipid metabolism and $\mathrm{pH}: \mathrm{A}^{31} \mathrm{P}$ nuclear magnetic resonance study in vivo and in vitro, Magn. Reson. Med. 41 (1999), 897-903.

[85] E.O. Aboagye and Z.M. Bhujwalla, Malignant transformation alters membrane choline phospholipid metabolism of human mammary epithelial cells, Cancer Research 59 (1999), 80-84.

[86] K. Natarajan, N. Mori, D. Artemov, E.O. Aboagye, V.P. Chacko and Z.M. Bhujwalla, Phospholipid profiles of invasive human breast cancer cells are altered towards a less invasive phospholipid profile by the anti-inflammatory agent indomethacin, Advan. Enzyme Regul. 40 (2000), 271-284.

[87] K. Natarajan, N. Mori, D. Artemov and Z.M. Bhujwalla, Exposure of Human Breast Cancer Cells to the Antiinflammatory Agent Indomethacin Alters Choline Phospholipid Metabolites and Nm23 Expression, Neoplasia 4 (2002), 409-416.

[88] T.-K. Tran, N. Sailasuta, R. Hurd and T. Jue, Spatial distribution of deoxymyoglobin in human muscle: An index of local tissue oxygenation, NMR Biomed 12 (1999), 26-30.

[89] T. Jue, Measuring tissue oxygenation with the ${ }^{1} \mathrm{H}$ NMR signals of myoglobin, in: NMR in physiology and biomedicine, R.J. Gillies, ed., New York: Academic Press, Inc., 1994, pp. 199-207.

[90] S. Schuder, J.B. Wittenberg, B. Haseltine and B.A. Wittenberg, Spectrophotometric determination of myoglobin in cardiac and skeletal muscle: Separation from hemoglobin by 
subunit-exchange chromatography, Analytical Biochemistry 92 (1979), 473-481.

[91] U. Kreutzer, D.S. Wang and T. Jue, Observing the ${ }^{1} \mathrm{H}$ NMR signal of the myoglobin Val-E11 in myocardium: An index of cellular oxygenation, Proc. Natl. Acad. Sci. USA 89 (1992), 4731-4733.

[92] U. Kreutzer and T. Jue, ${ }^{1} \mathrm{H}$-nuclear magnetic resonance deoxymyoglobin signal as indicator of intracellular oxygenation in myocardium, Am. J. Physiology 261 (1991), H20912097.

[93] T. Jue and S. Anderson, ${ }^{1} \mathrm{H}$ NMR observation of tissue myoglobin: An indicator of cellular oxygenation in vivo, Magn. Reson. Med. 13 (1990), 524-528.

[94] W. Chen, Y. Cho, H. Merkle, Y. Ye, Y. Zhang, G. Gong, J. Zhang and $\mathrm{K}$. Ugurbil, In vitro and in vivo studies of ${ }^{1} \mathrm{H}$ NMR visibility to detect deoxyhemoglobin and deoxymyoglobin signals in myocardium, Magn. Reson. Med. 42 (1999), 1-5.

[95] S.R. Arridge, Optical tomography in medical imaging, Inverse Problems 15 (1999), R41-R93.

[96] A. Shiino, M. Haida, B. Beauvoit and B. Chance, Threedimensional redox image of the normal gerbil brain, Neuroscience 91 (1999), 1581-1585.

[97] B. Chance, B. Schoener, R. Oshino, F. Itshak and Y. Nalase, Oxidation-reduction ratio studies of micochondria in freeze trapped samples, J. Biol. Chee. 254 (1979), 4764-4771.

[98] V. Ntziachristos, A.G. Yodh, M. Schnall and B. Chance, Concurrent MRI and diffuse optical tomography of breast after indocyanine green enhancement, Proc. Natl. Acad. Sci. USA 97 (2000), 2767-2772.

[99] B.W. Pogue, T.O. McBride, S. Osterman, S. Poplack, U. Osterberg and K.D. Paulsen, Quantitative hemoglobin tomography with diffuse near-infrared spectroscopy: pilot results in the breast, Radiology 218 (2000).

[100] A.V. Ratner, H.H. Muller, B.-B. Simpson, D.E. Johnson, R.E. Hurd, C. Sotak and S.W. Young, Detection of tumors with ${ }^{19} \mathrm{~F}$ magnetic resonance imaging, Invest. Radiol. 23 (1988), 361-364.

[101] G.N. La Mar, D.L. Budd and H. Goff, Assignment of proximal histidine proton NMR peaks in myoglobin and hemoglobin, Biochemical and Biophysical Research Communications 77 (1977), 104-110.

[102] D.J. Patel, L. Kampa, R.G. Shulman, T. Yamane and B.J. Wyluda, Proton nuclear magnetic resonance studies of myoglobin in $\mathrm{H}_{2} \mathrm{O}$, Proc. National Academy of Science 67 (1970), 1109-1115.

[103] G.N. La Mar, J.D. Cutnell and S.B. Kong, Proton magnetic resonance characterization of the dynamic stability of the heme pocket in myoglobin by the exchange behavior of the labile proton of the proximal histidyl imidazole, Biophysical J 34 (1981), 217-225.

[104] W.B. Mackinnon, P.A. Barry, P.L. Malycha, D.J. Gillett, P. Russell, C.L. Lean, S.T. Doran, B.H. Barraclough, M. Bilous and C.E. Mountford, Fine-needle biopsy specimens of benign breast lesions distinguished from invasive cancer ex vivo with proton MR spectroscopy, Radiology 204 (1997), 661-666.

[105] C.E. Mountford, R.L. Somorjai, P. Malycha, L. Gluch, C. Lean, P. Russell, B. Barraclough, D. Gillett, U. Himmelreich, B. Dolenko, A.E. Nikulin and I.C.P. Smith, Diagnosis and prognosis of breast cancer by magnetic resonance spectroscopy of fine-needle aspirates analysed using a statistical classification strategy, British Journal of Surgery 88 (2001), 1234-1240.

[106] G.M.K. Tse, H.S. Cheung, L.-M. Pang, W.C.W. Chu, B.K.B. Law, F.Y.L. Kung and D.K.W. Yeung, Characterization of
Lesions of the Breast with Proton MR Spectroscopy: Comparison of Carcinomas, Benign Lesions, and Phyllodes Tumors, Am. J. Roentgenol. 181 (2003), 1267-1272.

[107] J.-K. Kim, S.-H. Park, H.M. Lee, Y.-H. Lee, N.-K. Sung, D.-S. Chung and O.-D. Kim, In Vivo ${ }^{1} \mathrm{H}$-MRS Evaluation of Malignant and Benign Breast Diseases, The Breast 12 (2003), 179-182.

[108] P.J. Bolan, S. Meisamy, E.H. Baker, J. Lin, T. Emory, M. Nelson, L.I. Everson, D. Yee and M. Garwood, In Vivo Quantification of Choline Compounds in the Breast With ${ }^{1} \mathrm{H}$ MR Spectroscopy, Magn. Reson. Med. 50 (2003), 1134-1143.

[109] D.K.W. Yeung, H.S. Cheung and G.M.K. Tse, Human breast lesions: Characterization with contrast-enhanced in vivo proton MR spectroscopy-initial results, Radiology 220 (2001), 40-46.

[110] J.R. Roebuck, K.M. Cecil, M.D. Schnall and R.E. Lenkinski, Human breast lesions: Characterization with proton MR spectroscopy, Radiology 209 (1998), 269-275.

[111] N. Jagannathan, M. Kumar, V. Seenu, O. Coshic, S.N. Dwivedi, P.K. Julka, A. Srivastava and G.K. Rath, Evaluation of total choline from in vivo volume localized proton MR spectroscopy and its response to neoadjuvant chemotherapy in locally advanced breast cancer, British Journal of Cancer 84 (2001), 1016-1022.

[112] I.S. Gribbestad, T.E. Singstad, G. Nilsen, H.E. Fjosne, T. Engan, O.A. Haugen and P.A. Rinck, In vivo ${ }^{1} \mathrm{H}$ MRS of normal breast and breast tumors using a dedicated double breast coil, J. Magn. Reson. Img. 8 (1998), 1191-1197.

[113] K.A. Kvistad, I.J. Bakken, I.S. Gribbestad, B. Ehrnholm, S. Lundgren, H.E. Fjosne and O. Haraldseth, Characterization of neoplastic and normal human breast tissues with in vivo ${ }^{1}$ H MR spectroscopy, J. Magn. Reson. Imag. 10 (1999), 159164.

[114] D.K. Yeung, W.-T. Yang and G.M.K. Tse, Breast cancer: In vivo proton $\mathrm{MR}$ spectroscopy in the characterization of histopathologic subtypes and preliminary observations in axillary node metastases, Radiology 225 (2002), 190-197.

[115] E.H. Baker, P.J. Bolan, L. DelaBarre, H. Merkle, D. Yee, L.I. Everson and M. Garwood, Monitoring response to neoadjuvant chemotherapy for locally advanced breast cancer using $4{ }^{1}$ H MRS, Proc. Intl. Soc. Mag. Reson. Med. 10 (2002), 448.

[116] S. Meisamy, P.J. Bolan, K. Warren, E. Gulbahce, E.H. Baker, J.C. Lin, J.C. Nelson, D. Yee, T. Tuttle and M. Garwood, In vivo monitoring response to neoadjuvant chemotherapy in breast cancer: a quantitative comparison between high field MRI/MRS and Immunohistochemistry (Ki67), Proc. Int. Soc. Magn. Reson. Med. 11 (2003), 758.

[117] R. Katz-Brull, R. Margalit, P. Bendel and H. Degani, Choline metabolism in breast cancer; ${ }^{2} \mathrm{H}-,{ }^{13} \mathrm{C}-,{ }^{31} \mathrm{P}-\mathrm{NMR}$ studies of cells and tumors, Magnetic Resonance Materials in Physics, Biology, and Medicine 6 (1998), 44-52.

[118] P. Shkarin and Q. He, Lactate detection in human breast cancer on 2.1T MR system, Proc. Intl. Soc. Mag. Reson. Med. 9 (2001), 2327.

[119] Q. He, P. Shakarin and C.H. Lee-French, Mapping of Unsaturated lipid in Human Breast Cancer using Sel-MQC, Proc. Intl. Soc. Mag. Reson. Med. 11 (2003), 289.

[120] E.S. Pizer, C. Jackisch, F.D. Wood, G.R. Pasternack, N.E. Davidson and F.P. Kuhajda, Inhibition of fatty acid synthesis induces programmed cell death in human breast cancer cells, Cancer Research 56 (1996), 2745-2747.

[121] F.P. Kuhajda, K. Jenner, F.D. Wood, R. Hennigar, L.B. Jacobs, J.D. Dick and G.R. Pasternack, Fatty acid synthesis: 
a potential selective target for antineoplastic therapy, Proc. Natl. Acad. Sci. USA 91 (1994), 6379-6383.

[122] C.E. Mountford, W.B. Mackinnon, P. Russell, A. Rutter and E.J. Delikatny, Human cancers detected by proton MRS and chemical shift imaging ex vivo, Anticancer Research 16 (1996), 1521-1532.

[123] C.E. Mountford, C.L. Lean and W.B. Mackinnon, The use of proton NMR in cancer pathology, Annual Reports on NMR Spectroscopy 27 (1993), 173-215.

[124] S. Singer, M. Sivaraja, K. Souza, K. Millis and J.M. Corson, ${ }^{1} \mathrm{H}-\mathrm{NMR}$ detectable fatty acyl chain unsaturation in excised leiomyosarcoma correlate with grade and mitotic activity, $J$. Clin. Invest. 98 (1996), 244-250.

[125] C. Dowling, A.W. Bollen, S.M. Noworolski, M.W. McDermott, N.M. Barbaro, M.R. Day, R.G. Henry, S.M. Chang, W.P. Dillon, S.J. Nelson and D.B. Vigneron, Preoperative proton MR spectroscopic imaging of brain tumors: Correlation with histopathologic analysis of resection specimens, Am. J. Neuroadiol. 22 (2001), 604-612.

[126] D. Ott, J. Hennig and T. Ernst, Human brain tumors: Assessment with in vivo proton MR spectroscopy, Radiology 186 (1993), 745-752.

[127] M.J. Fulham, A. Bizzi, M.J. Dietz, H.H.-L. Shih, R. Raman, G.S. Sobering, J.A. Frank, A.J. Dwyer, J.R. Alger and G.D. Chiro, Mapping of brain tumor metabolites with proton MR spectroscopic imaging: clinical relevance, Radiology $\mathbf{1 8 5}$ (1992), 675-686.

[128] W.G. Negebdank, R. Sauter, T.R. Brown, J.L. Evelhoch, A. Falini, E.D. Gotsis, A. Heerschap, K. Kamada, B.C.P. Lee, M.M. Mengeot, E. Moser, K.A. Padavic-Shaller, J.A. Sanders, T.A. Spraggins, A.E. Stillman, B. Terwey, T.J. Vogl, K. Wicklow and R.A. Zimmerman, Proton magnetic resonance spectroscopy in patients with glial tumors: a multicenter study, J. Neurosurg. 84 (1996), 449-458.

[129] M.A.A.M. Heesters, R.L. Kamman, E.L. Mooyaart and K.G. Go, Localized proton spectroscopy of inoperable brain gliomas. Response to radiation therapy, J. Neuro-Oncology 17 (1993), 27-35.

[130] R. Tarnawski, M. Sokol, P. Pieniazek, B. Maciejewski, J. Walecki, L. Miszczyk and T. Krupska, ${ }^{1} \mathrm{H}-\mathrm{MRS}$ in vivo predicts the early treatment outcome of postoperative radiotherapy for malignant gliomas, Int. J. Radiation Oncology Biol. Phys. 52 (2002), 1271-1276.

[131] W. Moller-Hartmann, S. Herminghaus, T. Krings, G. Marquardt, H. Lanfermann, U. Pilatus and F.E. Zanella, Clinical application of proton magnetic resonance spectroscopy in the diagnosis of intracranial mass lesions, Neuroradiology 44 (2002), 371-381.

[132] A.A. Tzika, M.K. Zarifi, L. Goumnerova, L.G. Astrakas, D. Zurakowski, T. Young-Poussaint, D.C. Anthony, R.M. Scott and P.M. Black, Neuroimaging in pediatric brain tumors: GdDTPA-enhanced, hemodynamic, and diffusion MR imaging compared with MR spectroscopic imaging, Am. J. Neuroraiol. 23 (2002), 322-333.

[133] M. Law, S. Cha, E.A. Knopp, G. Johnson and A.W. Litt, High-grade gliomas and solidary metastases: differentiation by using perfusion and proton spectroscopic MR imaging, Radiology 222 (2002), 715-721.

[134] P.E. Sijens and M. Oudkerk, Diagnosing dural metastases, Neuroradiology 44 (2002), 275.

[135] M. Bendszus, M. Warmuth-Metz, R. Burger, R. Klein, J.C. Tonn and L. Solymosi, Diagnosing dural metastases: the value of ${ }^{1} \mathrm{H}$ magnetic resonance spectroscopy, Neuradiology 43 (2001), 285-289.
[136] R.A. Kauppinen, Monitoring cytotoxic tumour treatment response by diffusion magnetic resonance imaging and proton spectroscopy, NMR Biomed 15 (2002), 6-17.

[137] M. Harada, M. Uno, F. Hong, S. Hisaoka, H. Nishitani and T. Matsuda, Diffusion-weighted in vivo localized proton MR spectroscopy of human cerebral ischemia and tumor, NMR Biomed 15 (2002), 69-74.

[138] M.G. Swanson, D.B. Vigneron, T.-K.C. Tran and J. Kurhanewicz, Magnetic resonance imaging and spectroscopic imaging of prostate cancer, Cancer Investigation 19 (2001), 510-523.

[139] M. Roach III and J. Kurhanewicz, Spectroscopy in prostate cancer: hope or hype? Oncology 15 (2001), 1399-1410.

[140] J.A. Koutcher, K. Zakian and H. Hricak, Magnetic resonance spectroscopic studies of the prostate, Mol. Urol. 4 (2000), 143-152.

[141] H. Hricak, S. White, D. Vigneron, J. Kurhanewicz, A. Kosco, D. Levin, J. Weiss, P. Narayan and P.R. Carroll, Carcinoma of the prostate gland: MR imaging with pelvic phased-array coils versus integrated endorectal-pelvic phased-array coils, Radiology 193 (1994), 703-709.

[142] J. Scheidler, H. Hricak, D.B. Vigneron, K.K. Yu, D.L. Sokolov, L.R. Huang, C.J. Zaloudek, S.J. Nelson, P.R. Carroll and J. Kurhanewicz, Prostate cancer: localization with three-dimensional proton MR spectroscopic imagingclinicopathologic study, Radiology 213 (1999), 473-480.

[143] K.L. Zakian, S. Eberhardt, H. Hricak, A. Shukla-Dave, S. Kleinman, M. Muruganandham, K. Sircar, M.W. Kattan, V.E. Reuter, P.T. Scardino and J.A. Koutcher, Transition Zone Prostate Cancer: Metabolic Characteristics at ${ }^{1} \mathrm{H}$ MR Spectroscopic Imaging - Initial Results, Radiology 229 (2003), 241-247.

[144] J.F. Kayyem, R.M. Kumar, S.E. Fraser and T.J. Meade, Reporter-targeted co-transport of DNA and magnetic resonance contrast agents, Current Biology 2 (1995), 615-620.

[145] A.Y. Louie, M.M. Huber, E.T. Ahrens, U. Rothbacher, R. Moats, R.E. Jacobs, S.E. Fraser and T.J. Meade, In vivo visualization of gene expression using magnetic resonance imaging, Nature Biotechnology 18 (2000), 321-325.

[146] R.A. Moats, S.E. Fraser and T.J. Meade, A 'smart' magnetic resonance imaging agent that reports on specific enzymatic activity, Angew. Chem. Int. Ed. Engl. 36 (1997), 726-732.

[147] M. Modo, D. Cash, K. Mellodew, S.C.R. Williams, S.E. Fraser, T.J. Meade, J. Price and H. Hodges, Tracking transplanted stem cell migration using bifunctional, contrast agent-enhanced, magnetic resonance imaging, NeuroImage 17 (2002), 803-811.

[148] W. Richter, S. Lee, W.S. Warren and Q. He, Imaging with intermolecular multiple-quantum coherences in solution NMR, Science 267 (1995), 654.

[149] Q. He, W. Richter, S. Vathyam and W.S. Warren, Intermolecular multiple-quantum coherences and cross-correlations in solution NMR, J. Chem. Phys. 98 (1993), 6679-6800.

[150] W.S. Warren, W. Richter, A.H. Andreotti and B.T. Farmer II, Generation of impossible cross-peaks between bulk water and biomolecules in solution NMR, Science 262 (1993), 2005-2009.

[151] W. Dreher and D. Leibfritz, A new method for fast proton spectroscopic imaging: spectroscopic GRASE, Magn. Reson. Med. 44 (2000), 668-672.

[152] F. Hyder, R. Renken and D.L. Rothman, In vivo carbonedited detection with proton echo-planar spectroscopic imaging (ICED PEPSI): [3,4-(13) $\mathrm{CH}(2)]$ glutamate/glutamine to- 
mography in rat brain, Magn. Reson. Med. 42 (1999), $997-$ 1003.

[153] A.M.J. Hudson, W. Kockenberger, M. Heidenreich, N. Chandrakumar, R. Kimmich and R. Bowtell, ${ }^{1} \mathrm{H}$ detected ${ }^{13} \mathrm{C}$ echo planar imaging, J. Magn. Reson. 155 (2002), 64-71.

[154] B. Kuhn, W. Dreher, D.G. Norris and D. Leibfritz, Fast proton spectroscopic imaging employing k-space weigting achieved by variable repetition times, Magn. Reson. Med. 35 (1996), 457-464.

[155] U. Dydak, M. Weiger, K.P. Pruessmann, D. Meier and P. Boesiger, Sensitivity-encoded spectroscopic imaging, Magn. Reson. Med. 46 (2001), 713-722.

[156] S. Lee, G. Fichtinger and G.S. Chirikjian, Numerical algorithms for spatial registration of line fiducials from crosssectional images, Med. Phys. 29 (2002), 1881-1891.
[157] K. Masamune, G. Fichtinger, A. Patriciu, R.C. Susil, R.H. Taylor, L.R. Kavoussi, J.H. Anderson, I. Sakuma, T. Dohi and D. Stoianovici, System for robotically assisted percutaneous procedures with computed tomography guidance, Comput. Aided Surg. 6 (2001), 370-383.

[158] G. Fichtinger, T.L. DeWeese, A. Patriciu, A. Tanacs, D. Mazilu, J.H. Anderson, K. Masamune, R.H. Taylor and D. Stoianovici, System for robotically assisted prostate biopsy and therapy with intraoperative CT guidance, Acad. Radiol. 9 (2002), 60-74.

[159] R.J. Gillies, N. Raghunand, G.S. Karczmar and Z.M. Bhujwalla, MRI of the tumor microenvironment, J. Magn. Reson. Imag. 16 (2002), 430-450.

[160] L. Stryer, Biochemistry, W.H. Freeman: New York, 1988. 


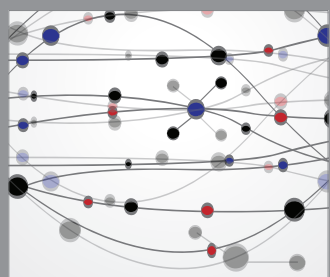

The Scientific World Journal
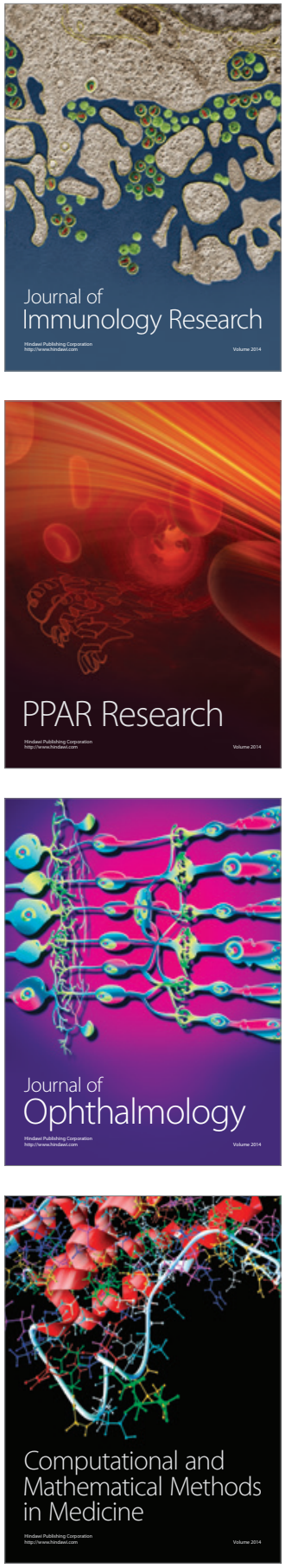

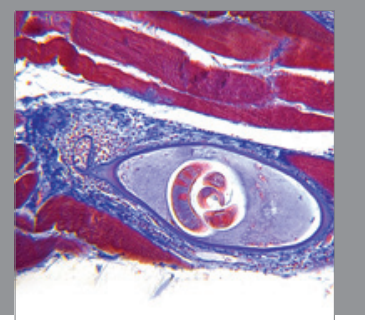

Gastroenterology

Research and Practice
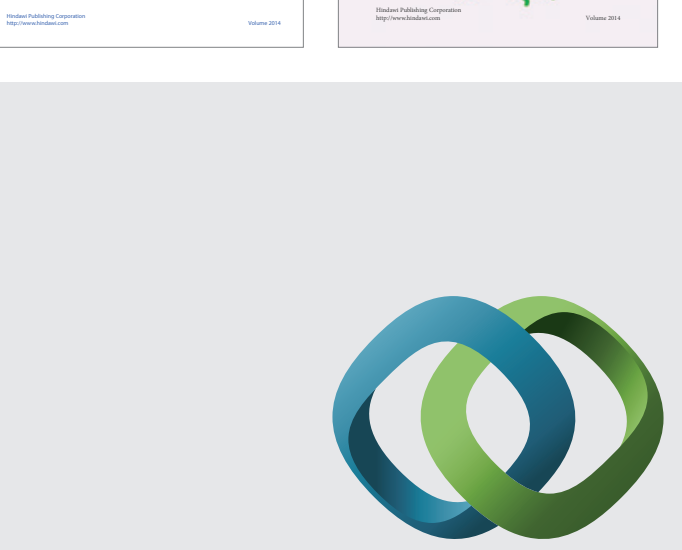

\section{Hindawi}

Submit your manuscripts at

http://www.hindawi.com
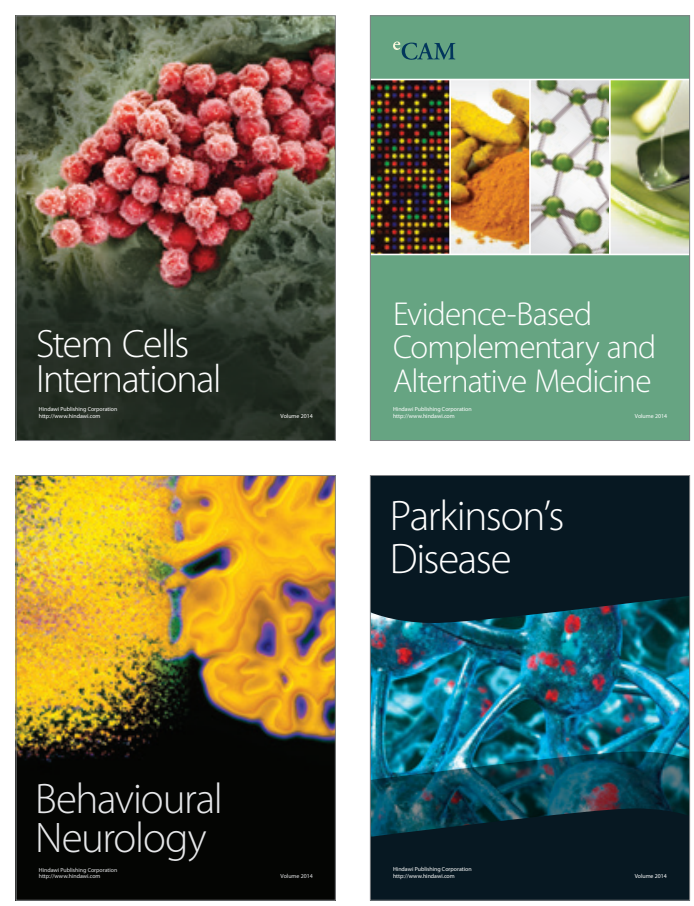

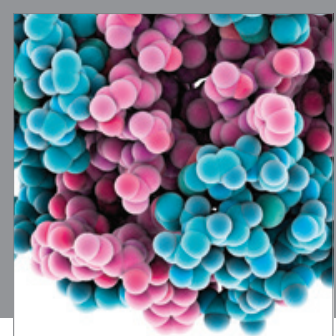

Journal of
Diabetes Research

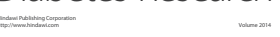

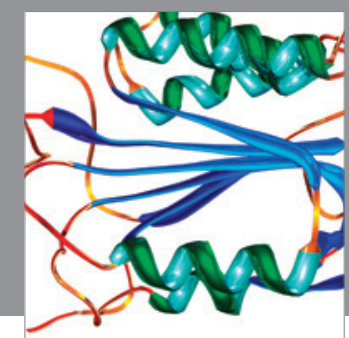

Disease Markers
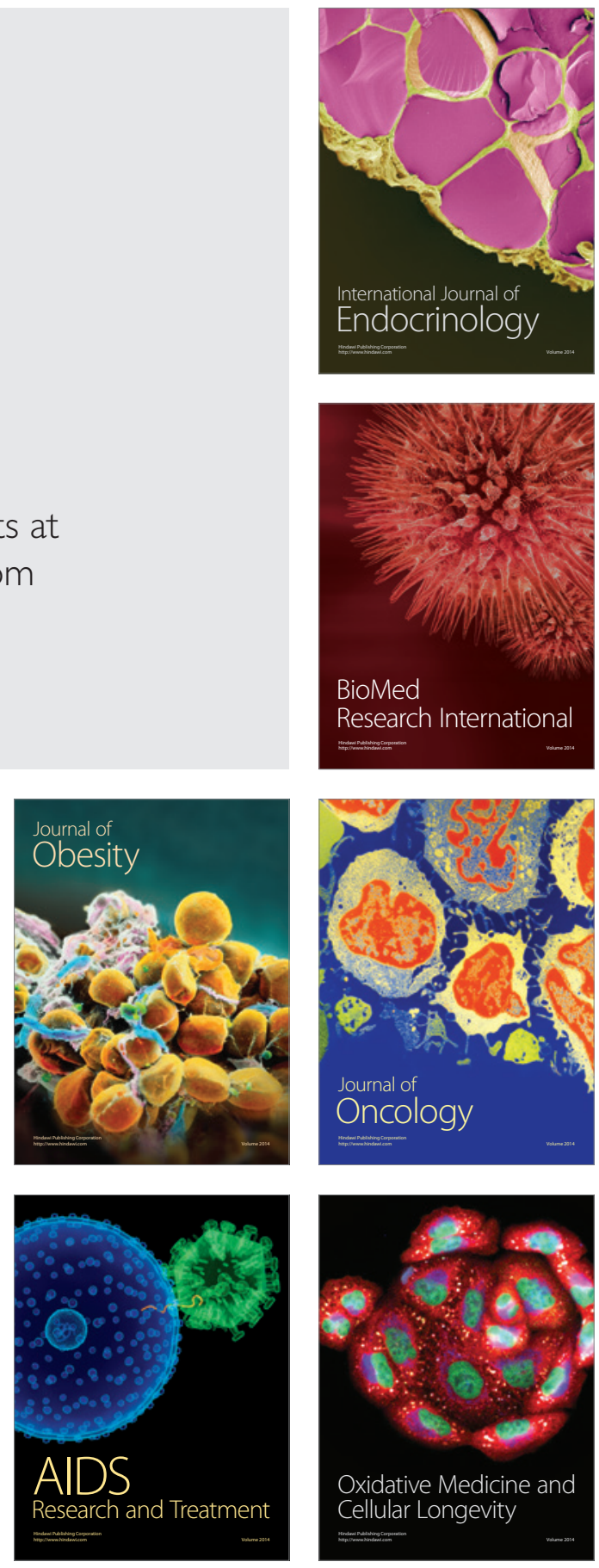